\title{
The Ganglionic Eminence May Be an Intermediate Target for Corticofugal and Thalamocortical Axons
}

\author{
Christine Métin and Pierre Godement \\ Institut Alfred Fessard, Centre National de la Recherche Scientifique UPR 2212, 91198 Gif-sur-Yvette, France
}

In the nervous system of many species, growing axons associate transiently with cellular groupings along their path. Whether this mechanism applies to the development of corticothalamic and thalamocortical projections is unknown. Using carbocyanine dyes, we studied the early growth of both corticofugal and thalamocortical fibers in hamster embryos. At embryonic day 11.5 (E11.5), corticofugal fibers invade the lateral ganglionic eminence (LGE), and thalamocortical fibers invade the medial ganglionic eminence (MGE). At this age, both sets of fibers are not yet in contact with each other. At the same time, neurons in each subdivision of the GE grow toward the cortex and thalamus. During the next $24 \mathrm{hr}$, corticofugal and thalamocortical fibers remain within the confines of the GE, where they course at different radial levels and bear large and complex growth cones. In the LGE, corticofugal fibers are often found in close association with cells that are likely to be neuronal. Starting on $\mathrm{E} 13.5$, both early projections from the GE decrease, and corticothalamic and thalamocortical fibers invade their definitive target regions. To test whether the GE specifically orients the growth and trajectories of cortical fibers even in the absence of the reciprocal thalamic projection, we cocultured explants of cortex and GE from either hamster or mouse embryos. These experiments showed that the GE, but not other tested brain regions, is able specifically to orient the growth of cortical axons. We therefore suggest that the GE may be an intermediate target in the pathfinding of axons between the cortex and the thalamus.

Key words: development; cortex; dorsal thalamus; basal telencephalon; early projections; guidance; axon outgrowth
Studies of axonal pathfinding in diverse species show that growing axons use several types of guidance cues, successively or in combination, to find the path toward their final target. Such cues are believed to be distributed continuously in the epithelia in which pioneer axons extend (Caudy and Bentley, 1986; Harris and Holt, 1990; Cornel and Holt, 1992) or to be present in a more restricted manner among cells and in the extracellular matrix along pathways (for review, see Dodd and Jessell, 1988; Goodman and Shatz, 1993). On a cellular level, changes in the course of growing axons, or sorting out among several types of fibers, are apparent in spatially restricted regions, termed "decision regions," and intermediate targets such as the motoneuronal plexus (Tosney and Landmesser, 1985; Tosney, 1991), the floor plate of the spinal cord (Tessier-Lavigne et al., 1988; Placzek et al., 1990; Yaginuma et al., 1993) and hindbrain (Shirasaki et al., 1995), and the optic chiasm (Godement et al., 1987, 1990; Wizenmann el al., 1993; Godement, 1994; Sretavan et al., 1994; Marcus et al., 1995). Such regions may secrete or display cues that ingrowing fibers use for their guidance (Felsenfeld et al., 1994; Serafini et al., 1994). In addition, several studies implicate the role of early neurons in guiding the growth of later-growing fibers or fibcrs originating from other areas (Ho and Goodman, 1982; Raper et al., 1983b; Ghosh et al., 1990; Wilson and Easter, 1991; Sretavan et al., 1994).

Received Nov. 21, 1995; revised Feb. 15, 1996; accepted Feb. 22, 1996

This work was supported by Institut National de la Santé et de la Recherche Médicale Grant CRE 910809 to C.M. and Centre National de la Recherche Scientifique Grant A.T.I.P.E.3 91N60/1057 to P.G. We thank Drs. Y. v. Boxberg and C. A. Mason for critically reading this manuscript, and Dr. J. M. Deniau for helpful comments on basal telencephalon organization. We are grateful to Drs. J.-P. Brion and $\mathrm{M}$. Thomasset for their generous gifts of antibodies. G. Ghilini provided expert assistance with immunocytochemistry, and J.P. Bouillot with photography.

Correspondence should be addressed to Dr. Christine Métin, Institut Alfred Fessard, CNRS Bat 33, 1, Avenue de la Terrasse, 91198 Gif-sur-Yvette, France. Copyright 1996 Society for Neuroscience $0270-6474 / 96 / 163219-17 \$ 05.00 / 0$
The earliest-projecting neurons might rely solely on cues within the neuroepithelium for their guidance, whereas later-projecting neurons could use a greater variety of cellular and molecular cues.

Selective axonal guidance by earlier-generated neurons is also implicated in the development of the long-distance pathways that reciprocally connect thalamic nuclei and cortical areas. A set of early-generated and transitory neurons in the cortex, the "subplate cells" (Kostovic and Molliver, 1974; Marin-Padilla, 1978; Luskin and Shatz, 1985; Bayer and Altman, 1990), could be involved in guiding thalamic fibers toward and into their cortical target areas (De Carlos and O'Leary, 1992; Ghosh and Shatz, 1992; Miller et al., 1993; for reviews, see O'Leary and Koester, 1993; Allendoerfer and Shatz, 1994; Molnàr and Blakemore, 1995). In carnivores, the axons of the subplate cells project toward the thalamus and could constitute a pioneer pathway that growing thalamic axons follow to reach the cortex (McConnell et al., 1989). Ablation of subplate neurons leads to a failure of thalamic fibers to recognize their normal cortical target areas (Ghosh et al., 1990). Because efferent cortical and afferent thalamic axons are segregated spatially in the intermediate zone of the developing cortical wall of rodents (Blakemore and Molnàr, 1990; De Carlos and O'Leary, 1992; Miller et al., 1993), interactions between both sets of fibers do not necessarily occur at this level in all species.

Although much is known about the development of corticofugal and thalamocortical fibers as they grow in the immediate vicinity of the cortex, several characteristics of the pathfinding between the thalamus and the cortex are little understood. In particular, how are the earliest corticofugal fibers themselves guided toward the thalamus? This question also applies to the guidance of the earliest thalamic fibers toward the cortex. As in other projection systems, information for the selective guidance of these fibers could be provided by cues along the trajectory followed by these 
fibers in the neuroepithelium and in defined regions. In fact, a putative intermediate target recently has been identified along the path between the neocortex and the dorsal thalamus in the rat. Cells from the reticular nucleus seem to provide pioneer axons to the dorsal thalamus. They could guide corticothalamic axons toward the thalamus and thalamocortical axons outside of the dorsal thalamus (Mitrofanis and Guillery, 1993).

In the present study, we used neuroanatomical tracing techniques to study the time course of development and the trajectories of thalamocortical projections in hamster embryos. Our aim was to identify characteristic features of the growth of these fibers at various sites between the thalamus and cortex. We also designed in vitro experiments to study the growth of corticofugal axons in the basal telencephalon in the absence of potential interactions with the reciprocal thalamocortical axons. Our observations suggest that the lateral and medial divisions of the embryonic ganglionic eminence (GE) could fulfill several important roles for guiding cortical and probably thalamic fibers in the early phase of progression to their respective targets.

\section{Abbreviations}

$G E$, ganglionic eminence

$L G E$, lateral ganglionic eminence

$M G E$, medial ganglionic cminence

\section{MATERIALS AND METHODS}

\section{Embryos}

Embryonic day 11 (E11) to E13 hamster embryos were used in tracing experiments, and E12-E13 mouse (C57BL/6J) embryos were used when immunostaining was associated with tracing studies. Animals were mated overnight in the laboratory. Mated mice were checked for the presence of vaginal plugs the next morning. The first day of gestation was termed cmbryonic day 0 , and it was noted E0 until noon and was E0.5 thercafter. Gestation lasted $16 \mathrm{~d}$ in hamsters and $19 \mathrm{~d}$ in mice.

Pregnant females were killed by an intraperitoneal injection of pentobarbital (hamster) or ether anesthesia and cervical dislocation (mouse). The pups were removed immediately by cesarean surgery, and their heads were immersed in cold fixative or culture medium, depending on experiments.

\section{Tracing experiments}

Carbocyanines were used as tracers in formaldehyde-fixed brains (Godement et al., 1987).

Brain fixation. After dissection in cold fixative (4\% paraformaldehyde in $0.1 \mathrm{M}$ phosphate buffer, $\mathrm{pH} 7.4$, at $4^{\circ} \mathrm{C}$ ) or cold culture medium (F12-DMEM with $8 \mathrm{~mm} \mathrm{D}+$ glucose and $14 \mathrm{mM} \mathrm{NaHCO}$, at $4^{\circ} \mathrm{C}$ ) or in cold PBS $\left(0.1 \mathrm{M}\right.$ at $\left.4^{\circ} \mathrm{C}\right)$, brains and flattened telencephalic vesicles were returned to the fixative for at least $4 \mathrm{~d}$ before dyes were injected.

Labeling. 1,1'-Dioctadecyl-3,3,3',3'-tetramethylindocarbocyanine perchlorate, $\mathrm{DilC}_{18}$ (3) (D-282, Molecular Probes) (Dil) or 4-(4-dihexadecylaminostyryl)- $N$-methylpyridinium iodide, 4-Di-16-ASP (D-3883, Molecular Probes) (DiA) was used. The signal/noise ratio is better with DiI, and therefore it was used more often. Small crystals of dye were applied to the pial surface of the embryonic neocortex or dorsal thalamus after the pia was removed, or tips of glass micropipettes coated with DiI or DiA were used to impale the tissue. When crystals were placed on the surface of the dorsal diencephalon, a thin film of paraplast was inserted between the diencephalon and the telencephalon to avoid diffusion of the dye. At each embryonic stage, approximately 15 brains received cortical injections ( 18 brains at E11.5, 16 at E12.5, 17 at E13.5), and 7 brains received thalamic injections ( 6 brains at E11.5, 7 at E12.5 and E13.5). The brains were then returned to fixative and kept for 6 weeks at room temperature before analysis or photoconversion.

Analysis of labeling. Whole brains were embedded in 3\% agarose, and serial sections were cut with a vibratome in the frontal planc. The thickness of sections varied from $60 \mu \mathrm{m}$ for the youngest brains to $100 \mu \mathrm{m}$ for the oldest. Sections were collected and kept in fixative (4\% paraformaldehyde in $0.1 \mathrm{M}$ phosphate buffer, $\mathrm{pH} 7.4$, at $4^{\circ} \mathrm{C}$ ). Before observation, they were rinsed and mounted in $0.1 \mathrm{M}$ phosphate buffer, $\mathrm{pH}$ 7.4. Some brains of the youngest embryos were dissected out, flattened, and observed as whole-mounted. The telencephalic vesicles were flattened after olfactory bulb and hippocampus were removed. The rest of the brain was separated into two halves by cutting along the midline. Flattened brains were mounted in glycerol/phosphate buffer $(9 \mathrm{vol}$ of glycerol/1 vol of phosphate buffer). We used a Zeiss epifluorescence microscope (Axioskop) for observations, camera lucida drawings, and microphotographs. Drawings of serial sections were used to reconstruct the trajectory of labeled fibers according to the location of the injection sitc. Landmarks including the pineal gland, the telodiencephalic sulcus, and the sulcus between the lateral ganglionic eminence (LGE) and the medial ganglionic eminence (MGE) were used as reference points for reconstruction.

Photoconversion of DiI labeling. Free-floating sections were pretreated for 30 min in $1 \% \mathrm{H}_{2} \mathrm{O}_{2}$ in PBS. They were preincubated for $10 \mathrm{~min}$ in 0.1 $\mathrm{M}$ Tris buffer at $\mathrm{pH} 8.2$, and then for 10 to $30 \mathrm{~min}$ in filtered ice-cold $0.15 \% \mathrm{DAB}$ in $0.1 \mathrm{~m}$ Tris buffer, $\mathrm{pH}$ 8.2. Thereafter, sections were transferred in a drop of fresh diaminobenzidine (DAB) solution under a Zeiss epifluorescence microscope (Axioskop) equipped with a $100 \mathrm{~W}$ HBO lamp and illuminated through a $10 \times$ objective (Fluar $10 \times$, NA 0.50 ) using a rhodamine filter set (Zeiss filter set 15). The DAB solution was changed every $10 \mathrm{~min}$; the photoconversion of DiI into a yellowbrown $\mathrm{DAB}$ precipitate was obtained in $40-90 \mathrm{~min}$. Sections were then rinsed in PBS for several hours, and either processed as free-floating for calbindin or Map2 immunostaining or mounted in glycerol/phosphate ( $\mathrm{vol} / \mathrm{vol})$ and viewed using Nomarski optics.

\section{Immunohistochemistry}

Immunostaining was performed on sections from mouse brain tissue because of the specificity of available antibodies (anti-Map2 and CaBP28K). Free-floating photoconverted sections and cryostat sections were processed.

Cryostat sections were prepared from embryonic brains fixed by immersion for $2-3 \mathrm{hr}$ in ice-cold $4 \%$ paraformaldehyde in $0.1 \mathrm{M}$ phosphate buffer, $\mathrm{pH} 7.4$, and then cryoprotected at $4^{\circ} \mathrm{C}$ overnight in $20 \%$ sucrose/ $0.1 \mathrm{M}$ phosphate buffer at $\mathrm{pII} 7.4$. The brains were frozen in $-50^{\circ} \mathrm{C}$ isopentane and serially cut on a cryostat at $15 \mu \mathrm{m}$ in the coronal plane.

Before immunostaining, sections were rinsed in $0.02 \mathrm{M}$ PBS, pH 7.4, and preincubated for $1 \mathrm{hr}$ in a blocking solution (4\% milk, $0.2 \%$ Triton $\mathrm{X}-100$ in PBS). Thereafter they were incubated in primary antisera overnight at room temperature. The concentrations of primary antisera were 1:500 and 1:1000 for the rabbit polyclonal anti-Map2 serum (serum B9; Brion et al., 1988) provided by Dr. J. P. Brion (Université Libre de Bruxelles, Laboratoire d'Anatomie Pathologique et de Microscopie Electronique, Bruxelles, Belgium) and 1:2000 and 1:3000 for the rabbit polyclonal anti-calbindin-28 kDa serum (Dechesne and Thomasset, 1988) provided by Dr. M. Thomasset (Inserm U120, Hôpital Robert Debré, Paris, France). Antisera were diluted in PBS containing $2 \%$ milk and $0.2 \%$ Triton $\mathrm{X}-100$. Sections were rinsed several times and processed for avidin-biotin-peroxidase immunostaining. They were incubated for $1 \mathrm{hr}$ in 1:200 biotinylated goat anti-rabbit $\operatorname{IgG}$ (Vector Laboratories) in PBS containing $2 \%$ milk and $0.2 \%$ Triton X-100. After three rinses in PBS, they were incubated for $1 \mathrm{hr}$ in avidin-biotin-horseradish peroxidase complex (ABC kit, Vector Laboratorics). The immunolabeling was revealed using $0.05 \%$ DAB, $0.02 \%$ nickel ammonium sulfate, and $0.01 \%$ $\mathrm{H}_{2} \mathrm{O}_{2}$ in $0.1 \mathrm{M}$ Tris buffer at $\mathrm{pH}$ 7.2. Nickel intensifies and colors gray the DAB precipitate. In photoconverted sections, therefore, the gray immunopositive cells were easily distinguishable from the DABphotoconverted DiI labeling.

Cryostat sections were dehydrated in alcohol, cleared in xylene, and coverslipped with permount. Double-labeled sections were mounted in glycerol/phosphate and viewed using Nomarski optics.

\section{Tissue culture}

Explants of telencephalic vesicles were prepared from E13 mouse or E12 hamster embryonic brains. Results obtained with mouse and hamster embryos were identical and were analyzed together. Embryos were dissected in cold culture medium (F12-DMEM, Gibco). The cortex and GE were separated from the rest of the telencephalic vesicle, and the pia was removed. They were kept attached together to prepare "whole" telencephalic vesicle explants (see Table 2, Fig. 10). For coculture experiments, the embryonic neocortex, lateral ridge, and medial ridge of the GE were transected. In half of the experiments, the ridges of the GE were kept attached to the ventral structures of the basal telencephalon; in the other half, the ridges were dissected from the rest of the basal telencephalon with thin tungsten needles. These two experimental conditions gave 


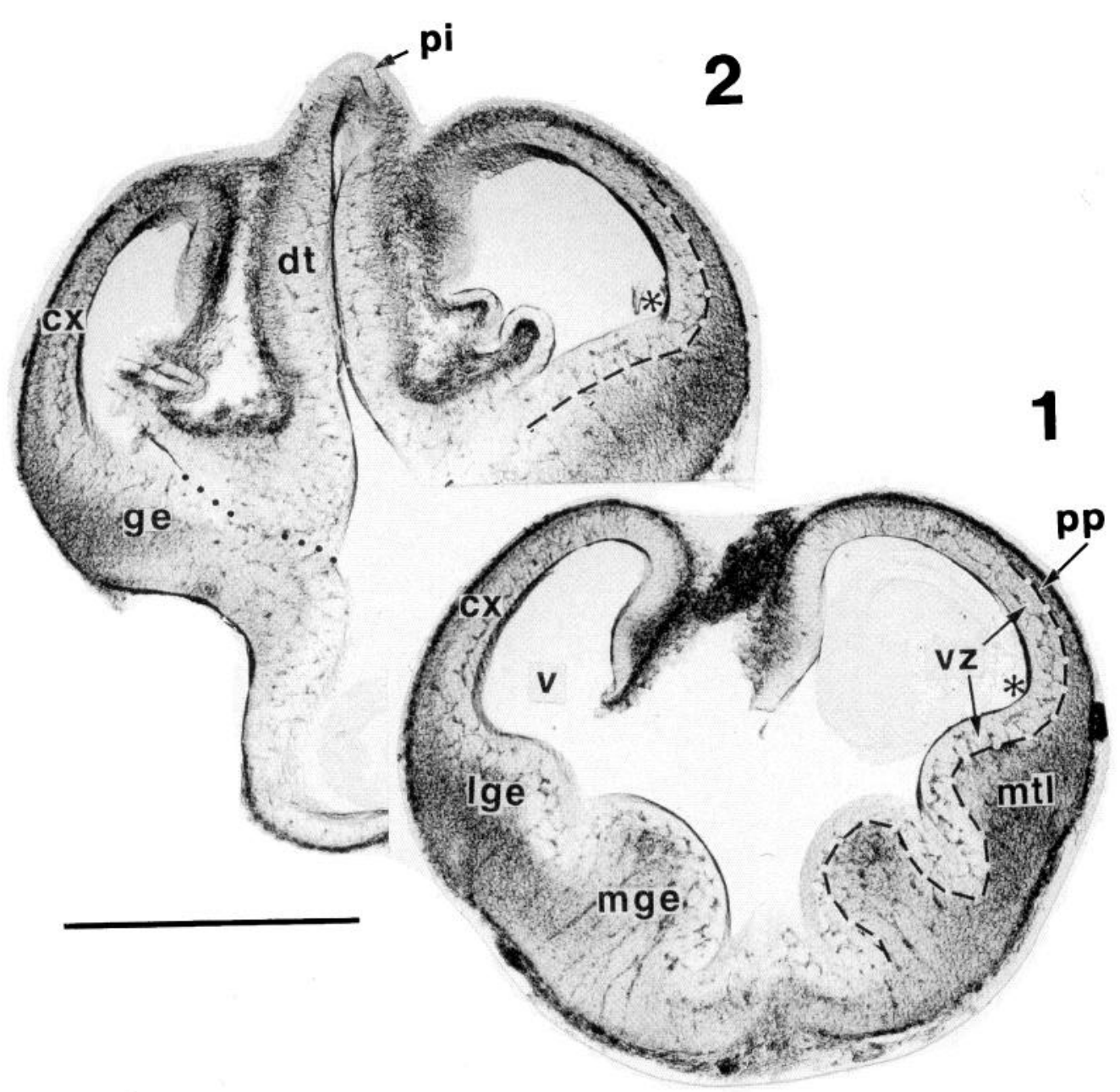

Figure 1. The main subdivisions of the forebrain on frontal, uncounterstained sections from an E11.5 hamster brain. The lateral and medial ridges of the GE are individualized clearly rostrally (section 1 ) and fuse caudally (section 2). Postmitotic cells are born in the ventricular zone (vz) and migrate in the preplate $(p p)$ at the pial side of the cortical wall $(c x)$ and in the mantle region $(m t l)$ of the GE. Asterisks indicate the ventricular angle. pi, Pineal gland; $d t$, dorsal thalamus; ge, ganglionic eminence; lge, lateral ganglionic eminence; mge, medial ganglionic eminence; $v$, ventricle. Scale bar, $1000 \mu \mathrm{m}$.

similar results and therefore were analyzed together. Control cocultures were made by placing an explant of neocortex next to an explant of neocortex, superior colliculus, or brainstem (region of pons).

Explants were transferred in a drop of medium onto nonpretreated microporous membranes in Millicell inserts CM (Millipore Corporation) and flattened with their ventricular side turned up. In cocultures between cortical explants and LGE or MGE explants, the two explants were placed side by side, either in their normal in vivo orientations or in different orientations (see Fig. 10, Table 2). Four to six explants or cocultures were placed in each Millicell insert before they were transferred in dishes containing the culture medium (F12-DMEM with $15 \mathrm{~mm}$ Hepes buffer, $14 \mathrm{~mm} \mathrm{NaHCO}, 33 \mathrm{~mm}$ glucose, $20 \mathrm{U} / \mathrm{ml}$ penicillin/ streptomycin, and $10 \%$ heat-inactivated neonatal bovine serum). Tissues were cultured at the interface air/medium for $4-5 \mathrm{~d}$ at $37^{\circ} \mathrm{C}$ in $5 \% \mathrm{CO}_{2}$. After fixation in $4 \%$ paraformaldehyde in $0.1 \mathrm{M}$ phosphate buffer, $\mathrm{pH} 7.2$, DiI crystals were inserted into the cortical wall to trace corticofugal fibers. Labeling was analyzed $4-6$ weeks later.

\section{RESULTS}

\section{Growth of corticofugal fibers}

To study the trajectories of corticofugal axons as well as possible interactions with cells along the way, we injected carbocyanine dyes in the cortex of fixed brains and combined dye tracing with immunohistochemistry. Injections of DiI or DiA were made at several sites in the cortex of E11.5-E13.5 hamster embryos.

\section{E11.5}

At this age, the cortical wall consists of the preplate above the thick germinative epithelium (Fig. 1). Pioneer cortical axons labeled from the lateral-most injection sites have left the embryonic neocortex, and their tips are observed within the LGE. At the frontier between the cortex and the LGE, the cortical axons have made a $90^{\circ}$ turn and shifted from a dorsoventral to a lateromedian trajectory (Fig. 2). These cortical fibers distribute within the mantle region of the LGE, where they end with large and complex growth cones. No labeled fibers were observed in the ventricular neuroepithelium of the GE. The longest axons were $\sim 800-900 \mu \mathrm{m}$ long.

Within the LGE, cortical fibers ran near or among sparsely distributed but strongly labeled cells, with very complex morphologies (Fig. 2A,C). Therefore, the LGE projects axons into the cortical wall at this early stage of development. Injections of DiI directly into the LGE confirm this point. After such injections, labeled LGE fibers were seen to project into the cortical wall, often for long distances.

\section{E12.5}

The entire tangential extent of the neocortex has now projected axons that have extended beyond the lateral border of the cortical 


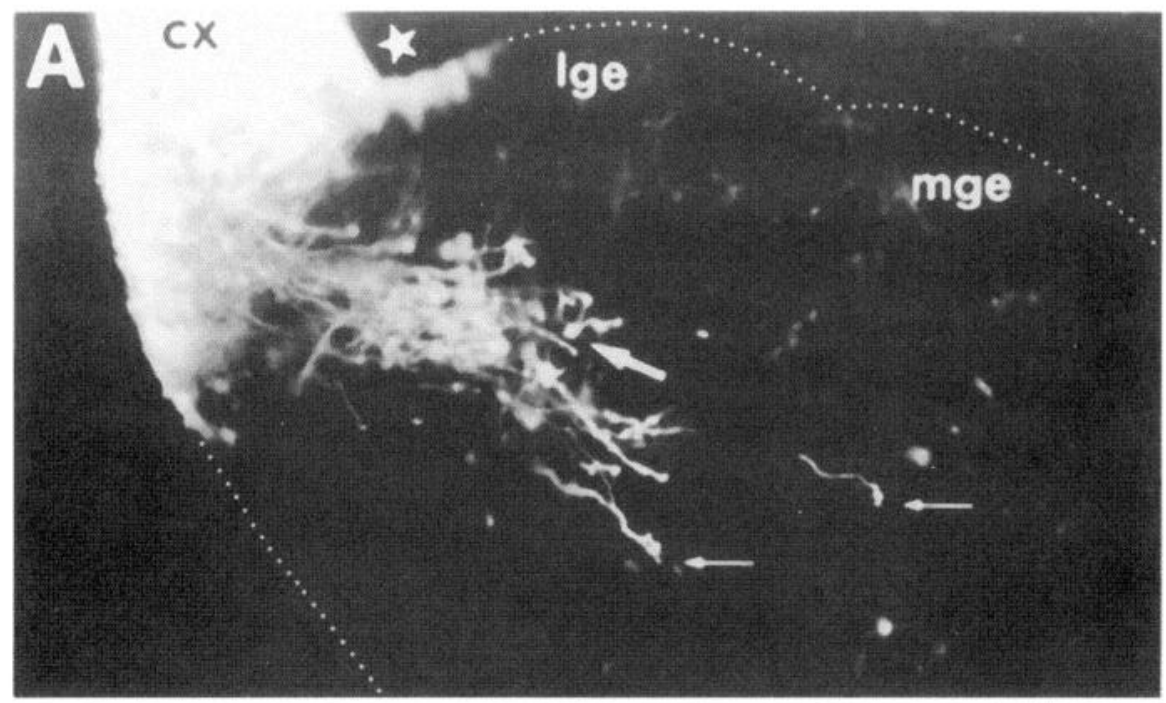

Figure 2. Labeling in the basal telencephalon of an E11.5 hamster brain injected with DiI in the lateral cortical wall $(c x)$ and DiA in the dorsal thalamus. $A$, $B$, The same frontal section is shown viewed through filter sets for $\mathrm{DiI}(A)$ or $\mathrm{DiA}(B)$. Dotted lines indicate the outlines of the section. $A$, Dil-labeled corticofugal axons leave the embryonic neocortex at the ventricular angle and turn into the mantle of the LGE. Within the LGE, fibers bear complex growth cones (thin arrows) and are mixed with labeled cell bodies (large arrow). The star indicates the ventricular angle. B, Axons and cell bodies (large arrow) labeled with DiA are located in the mantle region of the MGE, close to the junction with the diencephalon. The arrowheads point to two thalamic growth cones, and thin arrows point to corticofugal fibers faintly visible through the DiA filter. $C$, High-magnification view of corticofugal fibers and of a cell (arrow) in the mantle of the LGE. Scale bars: $A, B, 200 \mu \mathrm{m} ; C, 50 \mu \mathrm{m}$.
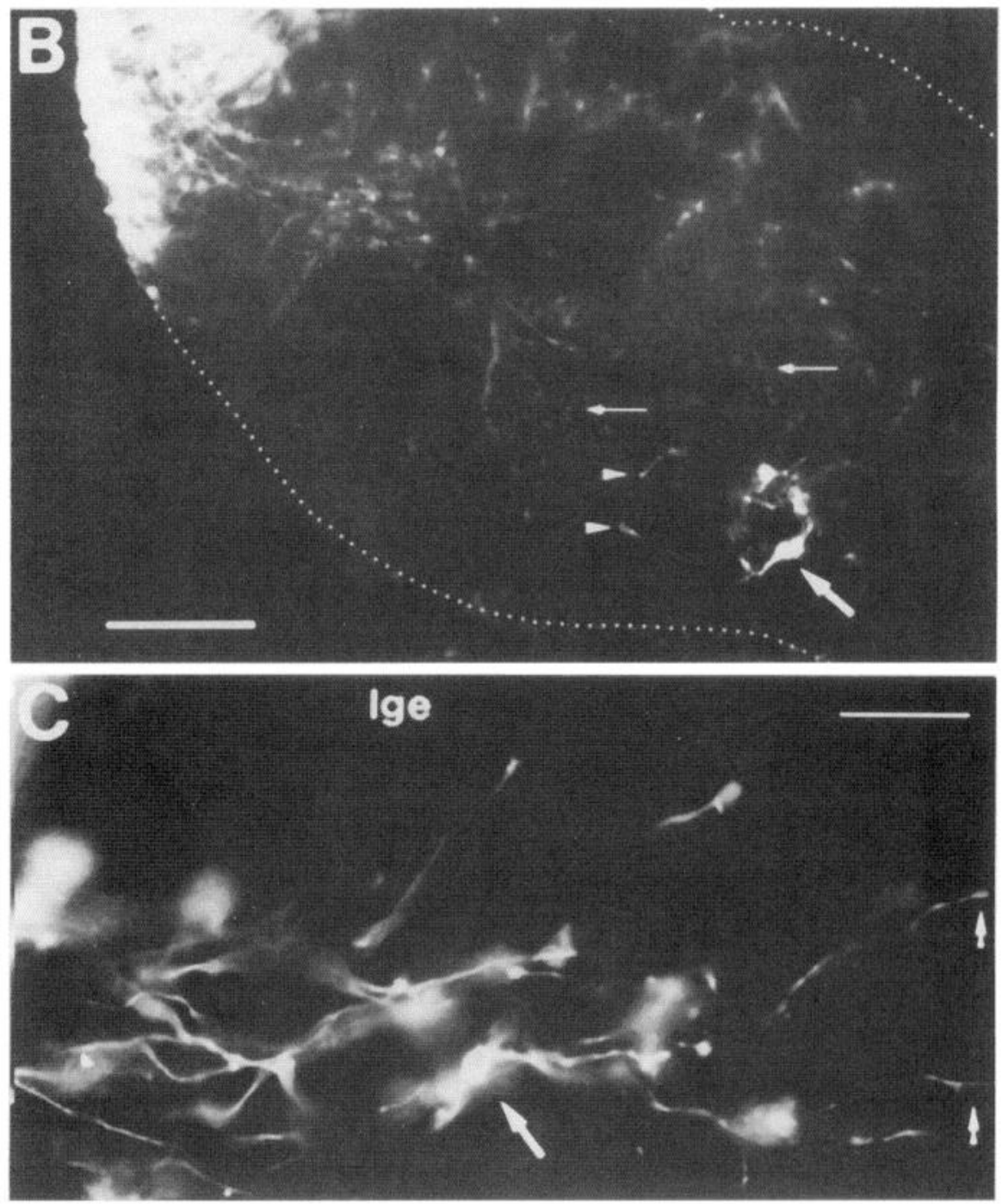
Table 1. Furthest extent of fibers after cortical or thalamic injections in hamster embryos

\begin{tabular}{|c|c|c|c|c|c|c|c|c|c|}
\hline & \multicolumn{3}{|l|}{ E11.5 } & \multicolumn{3}{|l|}{ E12.5 } & \multicolumn{3}{|l|}{ E13.5 } \\
\hline & Neocortex & $\mathrm{GE}$ & Thalamus & Neocortex & $\mathrm{GE}$ & Thalamus & Neocortex & $\mathrm{GE}$ & Thalamus \\
\hline \multicolumn{10}{|c|}{ Cortical injections } \\
\hline$n$ & 12 & 6 & 0 & 2 & 13 & 0 & 1 & 11 & 3 \\
\hline$\%$ & 67 & 33 & 0 & 13 & 87 & 0 & 7 & 73 & 20 \\
\hline \multicolumn{10}{|c|}{ Thalamic injections } \\
\hline$n$ & 0 & 5 & 3 & 1 & 5 & 0 & 7 & 0 & 0 \\
\hline$\%$ & 0 & 62 & 38 & 17 & 83 & 0 & 100 & 0 & 0 \\
\hline
\end{tabular}

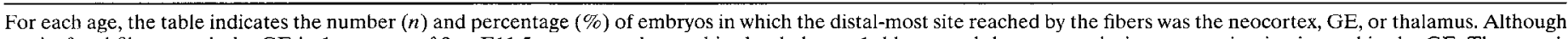

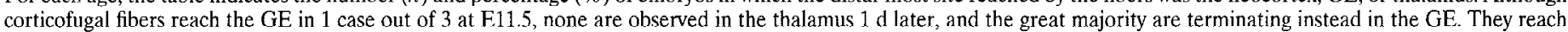

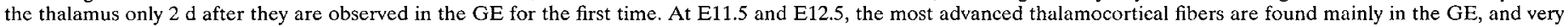
few are found in the cortex. At E13.5, projections into the cortex are observed in all experimental cases analyzed.

wall and into the basal telencephalon (Table 1). At the ventricular angle of the telencephalic vesicle, cortical fibers had crossed the intermediate zone of the cerebral wall and entered the LGE. They were observed in the whole dorsoventral and lateromedial extent of the mantle region of the LGE, they were defasciculated (Fig. $3 A$ ), and most of them ended with wide and foliate growth cones. As at E11.5, the growth cones in the LGE were often bifurcated and large, giving them a more complex appearance than growth cones in the intermediate zone of the cortical wall (compare Fig. $5, F$ and $D$, right). Only a small proportion of the fibers extended in the dorsal part of the MGE; most remained confined within the LGE. No fibers were observed in the dorsal diencephalon at this age. In the LGE, retrogradely labeled cells were again observed, in higher numbers than at E11.5 (Fig. 3A,C). They were much less numerous in caudal than in rostral regions of the GE. Labeled cells were also observed occasionally in the intermediate zone of the cortical wall, mixed with the corticofugal fibers (Fig. 3B). They generally had large and elongated cell bodies, oriented parallel to the fibers.

\section{E13.5}

At this age, large numbers of labeled cortical fibers were observed beyond the embryonic striatum that differentiated in the LGE (Fig. $4 A$ ), and the most advanced had already reached the dorsal thalamus (Table 1). In the cortical wall, most fibers ran in a widespread stream within the intermediate zone, and a thin fascicle of efferent fibers ran within the subplate. The stream of corticofugal axons enlarged as it reached the lateral part of the embryonic striatum and then condensed again to form the internal capsule in the medial part of the basal telencephalon. Labeled cell bodies were still observed in the embryonic striatum, but their density strongly decreased compared with E12.5.

\section{Cellular environment of the growing cortical axons at the ventricular angle and into the LGE}

We studied the cellular environment of corticofugal axons in the LGE and at the ventricular angle when these fibers still navigate into the LGE and are closely associated to sparse, retrogradely labeled cell bodies. Because few antibodies are available that react well with antigens in hamsters, immunohistochemistry was performed in E13 mouse embryos, a developmental stage that corresponds to the beginning of E12 in hamster embryos.

We used an antibody that recognizes a juvenile form of the neuronal marker Map2 in mouse embryos (Brion et al., 1988). On frontal sections from E13 mouse brains, cells strongly stained for Map2 were found in the lower half of the intermediate zone (Fig.
$5 A$ ). They showed a tangential arrangement, although they occasionally sent a few oblique or radial processes toward the ventricular zone or the overlying cortical plate. At the ventricular angle, they coursed around the fold of the neuroepithelium. This "stream" of tangential cells ended or changed its arrangement at the lateral border of the GE, where a narrow dorsoventral band contained a high density of Map2-positive cells (Fig. 5A). Elsewhere in the mantle zone of the GE, stained cells were few and sparsely distributed throughout the whole lateromedian extent. As seen in photoconverted Dil-labeled sections, the trajectory of the cortical axons at the ventricular angle matches the distribution of Map2-positive neurons. In the LGE, the dye-labeled cortical fibers and cells were distributed among differentiating neurons in the mantle zone, which weakly expressed Map2 (Fig. 5B).

Cells strongly expressing CaBP $28 \mathrm{~K}$ and bearing processes oriented in several directions were also observed among growing corticofugal fibers at the ventricular angle and in the mantle zone of the LGE (Fig. 5C). Near the front of growth of the cortical axons, we frequently observed DiI-labeled fibers closely apposed to CaBP28K positive cell bodies (Fig. $5 D, F$ ), some of which had neuronal morphologies (Fig. $5 D$ ). These immunostained cells were never DiI-labeled.

\section{Growth of thalamocortical fibers}

At the same time that corticofugal fibers grow, first toward the $\mathrm{GE}$, then into the thalamus, thalamocortical fibers pioneer the reciprocal pathway and invade the cortex.

\section{E11.5}

Injections in the dorsal thalamus labeled a large fascicle of fibers that coursed toward the telodiencephalic sulcus, but only a few fibers had reached the MGE at this time (Fig. 2B). Double injections of DiI in the cortical wall and of DiA in the thalamus showed that the pioneer cortical and thalamic fibers (labeled from injections in the parietal cortex and the ventral part of the dorsal thalamus, respectively) had just met one another in the MGE, close to the telodiencephalic sulcus (Fig. 2; compare Figs. 7 and 8 ). Labeled cell bodies were always found in small groups near the tips of thalamic fibers in the mantle zone of the MGE (Fig. 2B).

\section{E12.5}

Fibers labeled from the dorsal thalamus reached the embryonic striatum, where they seemed to be less scattered than the cortical fibers (Fig. 6). Their growth cones accumulated at the border between the embryonic striatum and the lateral cortical wall. Double-labeling experiments confirmed that both cortical and 

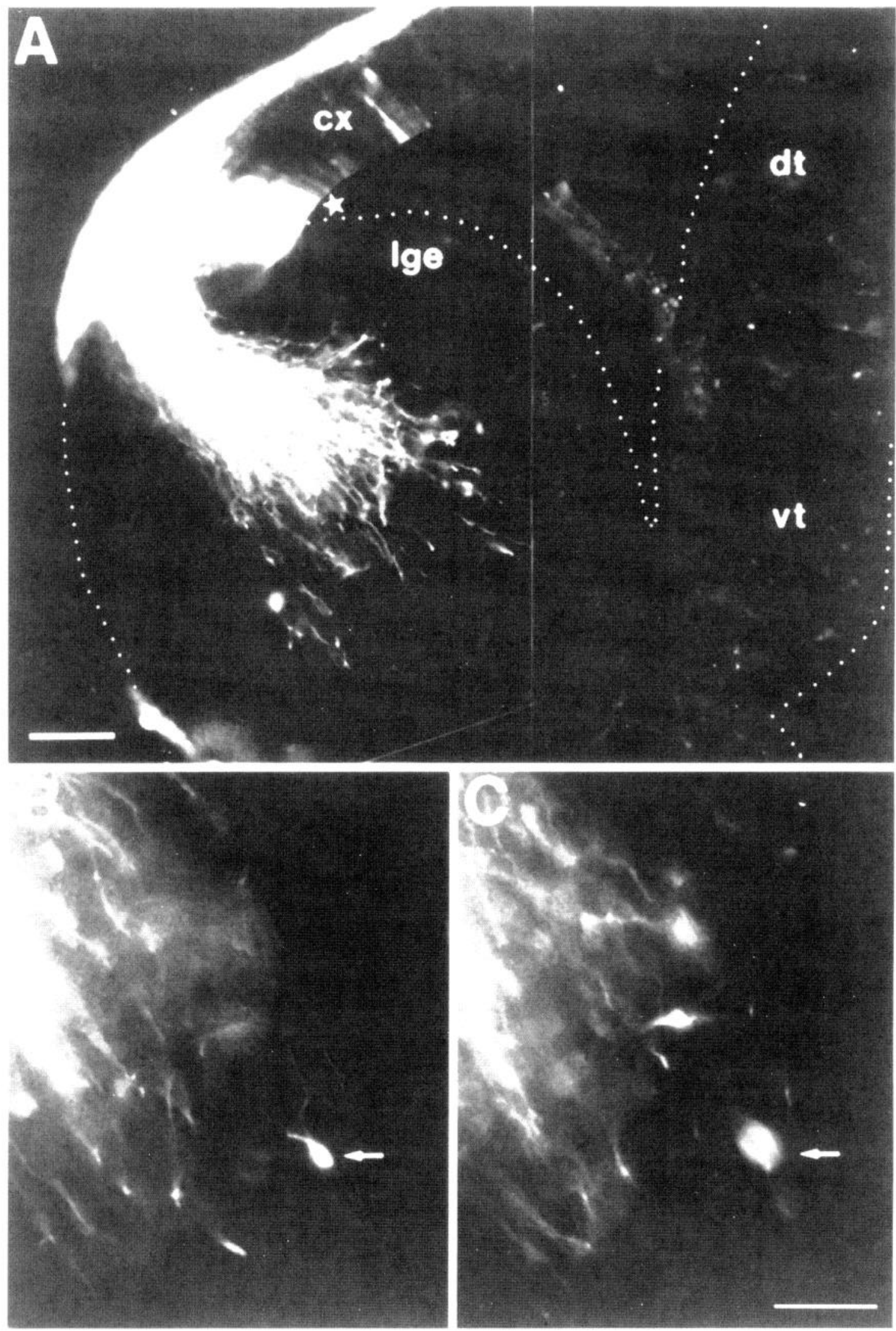

Figure 3. Labeling in the telencephalon of E12.5 embryos after DiI injections in the cortical wall $(c x)$. A, Cortical fibers end with complex growth cones in the lateral part of the GE. A very small number of fibers extend in the medial part of the GE. Dotted lines indicate the outlines of the section, and the star indicates the ventricular angle. $B, C$, Retrogradely labeled cells observed in the mantle of the GE, near the front of growth of efferent cortical fibers. The focus was changed between the two plates, and arrows show the same cell. Scale bars: $A, 200 \mu \mathrm{m} ; B, C, 50 \mu \mathrm{m}$. 

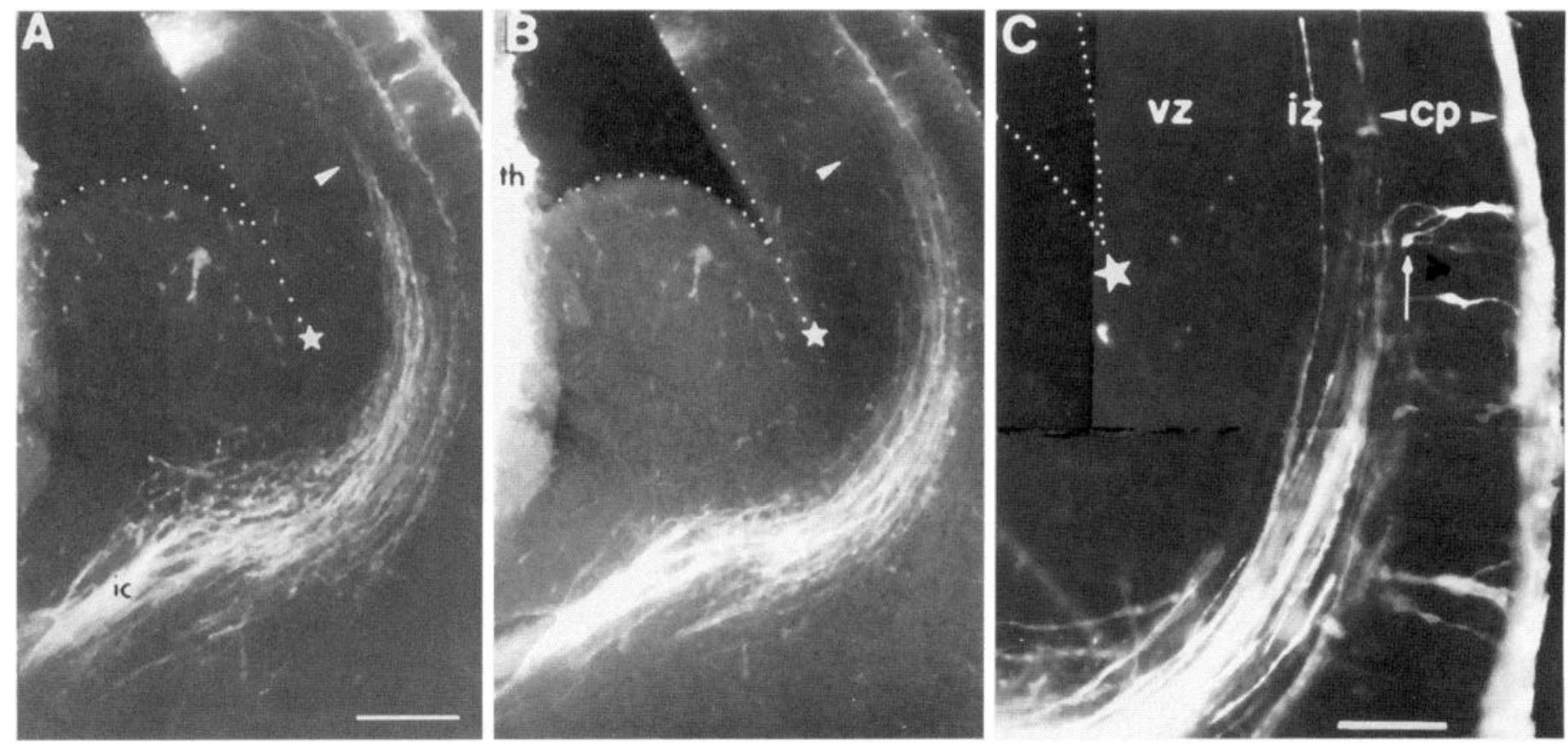

Figure 4. Labeling in the telencephalon of E13.5 embryos after dye injections in the cortical wall and in the dorsal thalamus. $A, B$, Labeling is shown in the basal telencephalon of an E13.5 embryo injected with DiI in the lateral neocortex and with DiA in the dorsal thalamus. $A$, DiI-labeled corticofugal axons form a thin fascicle in the subplate and a deep broader bundle in the intermediate zone (iz). In the basal telencephalon, they spread out in the dorsoventral direction and then condense to form the internal capsule (ic). B, DiA-labeled thalamic axons form a thick bundle in the basal telencephalon and reach the upper part of the intermediate zone in the cortical wall. $C$, Retrogradely labeled cells in the lateral cortex, from an injection site in the dorsal thalamus. The cells are distributed within the whole radial extent of the cortical plate $(c p)$, and most of them are elongated radially and have a dendritic tree oriented toward the surface of the cortex. One of them (vertical arrow) is located at the basis of the $\mathrm{cp}$, where the subplate begins to differentiate at this stage. The star indicates the ventricular angle, and the small and large arrowheads point to the same blood vessels in $A$ and $B$.Dotted lines indicate the outlines of sections. $i c$, Internal capsule; $t h$, thalamus; $v z$, ventricular zone; $i z$, intermediate zone. Scale bars: $A, 200 \mu \mathrm{m} ; C, 100 \mu \mathrm{m}$.

thalamic fibers were present in the lateral part of the GE. In the medial part of the GE, cortical fibers ran dorsal to the thalamic fibers.

As in E11.5 embryos, dye injections in the dorsal thalamus labeled a few cells in the MGE, below and within the internal capsule (Fig. 6A,C).

\section{E13.5}

At this age, thalamic fibers were distributed widely within a large anteroposterior domain of the cortical wall. Fibers traversed the intermediate zone of the lateral part of the cortical wall and reached the upper half of the intermediate zone and the subplate, but did not yet enter the cortical plate (Fig. $4 B$ ).

\section{Topographical organtion of the early corticofugal projection in the telencephalic vesicle}

At E11.5, the trajectories of corticofugal axons in the telencephalic vesicle, as reconstructed from frontal sections or analyzed on flattened vesicles (Fig. 7), were oriented coarsely dorsoventrally, orthogonal to the rostrocaudal axis of the telencephalic vesicle; however, cortical fibers arising from the caudal-most sites made a rostral turn soon after entering the LGE. One day later, at E12.5, most cortical axons still ended in the lateral part of the basal telencephalon. The most advanced reached the MGE, and in the last part of their trajectory were deflected into the rostrocaudal plane to converge toward the telodiencephalic sulcus. At E13.5, cortical fibers labeled from the presumptive parietal cortex entered the dorsal thalamus. Thalamic injections, in contrast, retrogradely labeled cortical plate and subplate cells within a small lateral area of the presumptive parietal neocortex (Fig. 4C). Fibers labeled from other cortical areas had already reached the internal capsule but not the dorsal diencephalon. At E13.5, and in a few E12.5 embryos, cortical injections also labeled axons whose trajectories in the basal telencephalon diverged from those described above and illustrated in Figure 7. We did not study the trajectories of these fibers.

In summary, the dye-labeling shows that the corticofugal and thalamocortical axons grow out at the same time and simultaneously reach the GE. Rather than interacting with each other, both sets of fibers seem to interact with substrate in the LGE and MGE. At same time, the LGE sends reciprocal projections toward the cortex, and the MGE sends them toward the thalamus. After a waiting period of $\sim 24 \mathrm{hr}$, the cortical and thalamic projections leave the GE to reach their final targets, and the efferent projections from the GE decrease.

\section{Coculture experiment with the cortex and GE}

The anatomical observations suggested that cortical and thalamic fibers use the GE as an intermediate target. To test whether the GE could specifically orient the growth of at least the corticofugal axons, we conducted coculture experiments. First, we examined the development of pathways within large explants comprising most of the telencephalic vesicle (cortex $+\mathrm{GE})$. We then made several types of cocultures, in which a cortical explant was placed next to an explant of the entire GE or of only the LGE or MGE, as well as control cocultures in which the cortical explant was placed next to a collicular, brainstem, or cortical explant (Table 

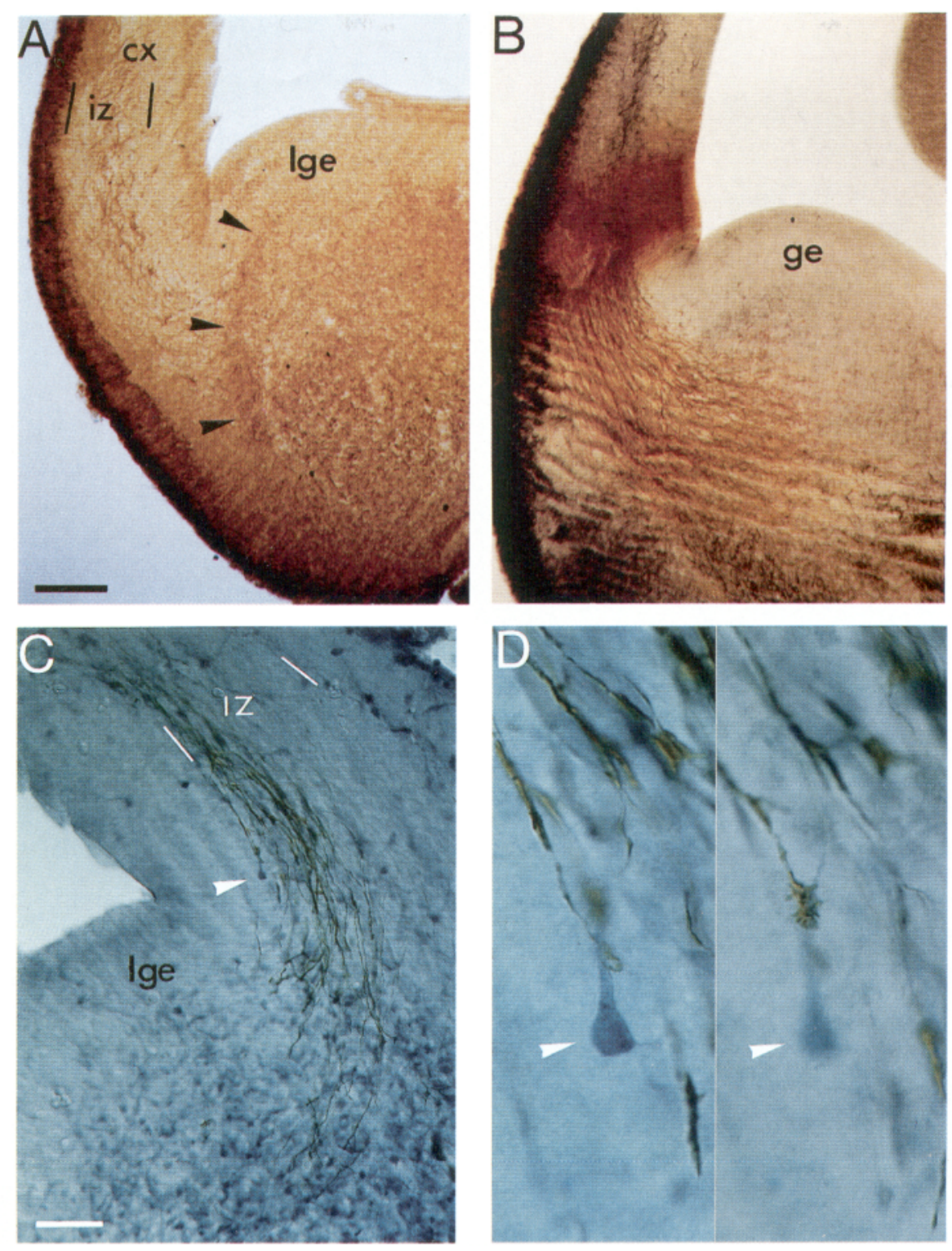

Figure 5. Combined Map2 and CaBP28K immunostaining together with photoconverted DiI-labeled corticofugal fibers in E13.5 mouse brains. $A$, In the cortical wall, MAP-2 positive neurons (brown) are distributed in the cortical plate and in the lower half of the intermediate zone (iz). A narrow and dense stripe containing strongly positive neurons is seen at the lateral border of the LGE (lge; arrowheads). In the rest of the LGE, positive cells are less dense and more weakly stained. $B$, Double-labeled section showing photoconverted DiIlabeled corticofugal axons (brown) and Map2-positive cells (gray) in the GE (ge). C, Cortical fibers (brown) run among CaBP28K-positive cells (dark blue) in the lower part of the iz, at the ventricular angle and in the mantle zone of the LGE. White marker points to the CaBP28Kpositive cell shown in $D . D$, Two high-magnification views of a CaBP28K-positive cell with two growth cones closely apposed to the same process. E, Highmagnification view of a retrogradely labeled cell at the lateral border of the LGE. $F$, Two cortical fibers (black arrowheads) are shown closely apposed to a CaBP28Kpositive cell body in the LGE. Growth cones in the vicinity exhibit very complex morphologies. Scale bars:
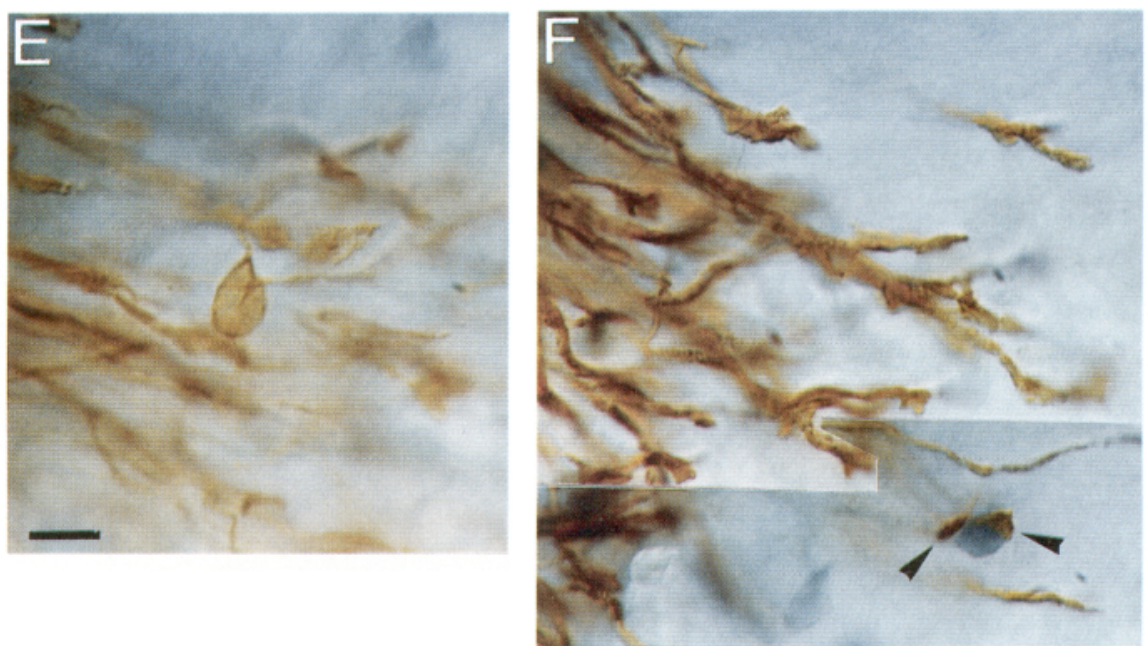
$A, 100 \mu \mathrm{m} ; D, 50 \mu \mathrm{m} ; C, E, F, 10 \mu \mathrm{m}$. 

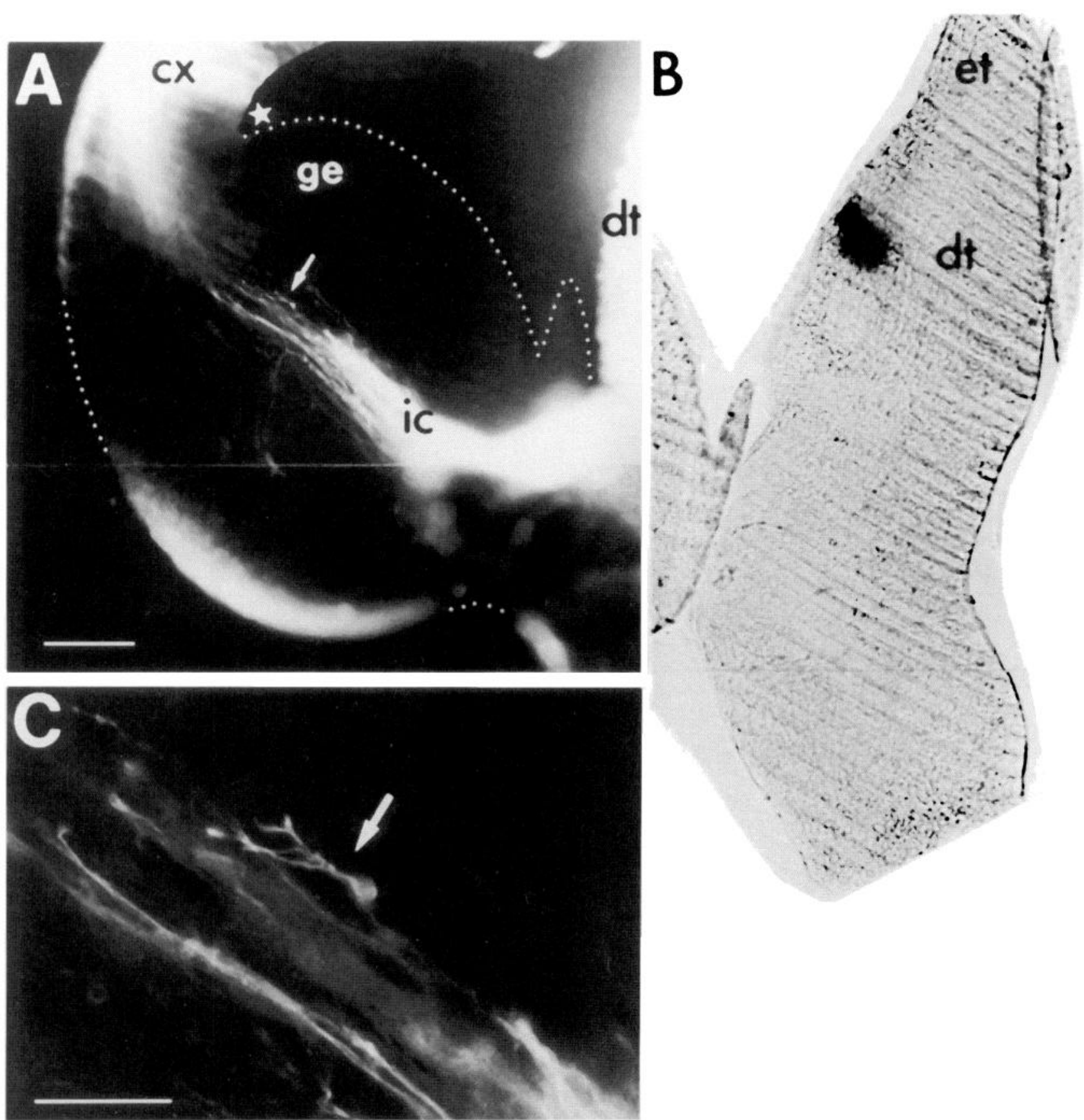

Figure 6. Frontal sections from the basal telencephalon of an E12.5 hamster embryo injected with DiI into the dorsal thalamus $(d t)$. $A$, Low-magnification view of thalamic axons in the internal capsule (ic). The cortical wall $(c x)$ received an injection of DiA, faintly visible though this filter. Thalamic axons end with growth cones close to the lateral border of the GE (ge). A cell (large arrow) observed near thalamic axons in the ic is shown at high-magnification in $C$. B, A more caudal section containing the center of the injection site. The DiI crystal appears as a dark rectangle. et, Epithalamus. Scale bars: $A, B$, $200 \mu \mathrm{m} ; C, 50 \mu \mathrm{m}$.

2). After $4-5 \mathrm{~d}$ in vitro, the cultures were fixed, and fibers originating in the cortical explant were traced using DiI.

\section{Growth of fibers within explants of the entire telencephalic vesicle}

We assessed whether cortical-GE projections developed when the cortical wall and GE were kept attached together and cultured on a Millicell filter. After $4-5 \mathrm{~d}$ in culture, the telencephalic vesicle explants underwent some enlargement and distortions. The two ridges of the GE became less apparent, but the cortex was still thinner than the GE and clearly distinguishable from the adjacent
LGE (Fig. 8A). Injections of DiI in the cortex labeled cortical axons, most of which ended in the LGE. The majority followed rather straight trajectories oriented toward the center of the GE, and a small proportion of them reached a small area located below the LGE in the center of the GE and grew around or within it (Fig. 8B). After $4 \mathrm{~d}$ in vitro, the pattern of cortical fibers was remarkably similar to that observed in vivo between E11.5 and E13.5 (see Fig. 7): (1) They followed dorsoventral trajectories up to the LGE, where a large number of them accumulated, and (2) those that left the LGE converged toward a restricted region of 


\section{CORTICAL INJECTIONS}

\section{dorsal view}

E11.5

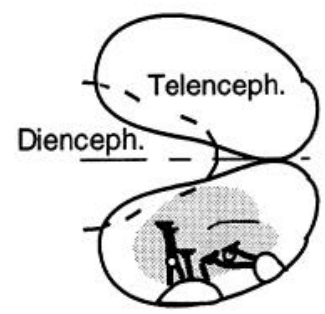

E12.5

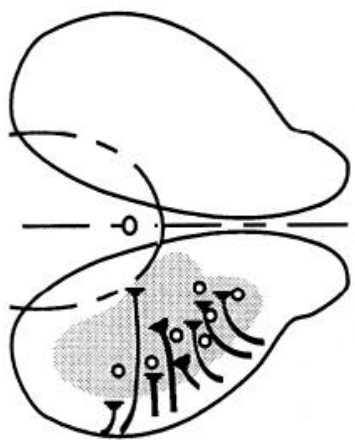

E13.5

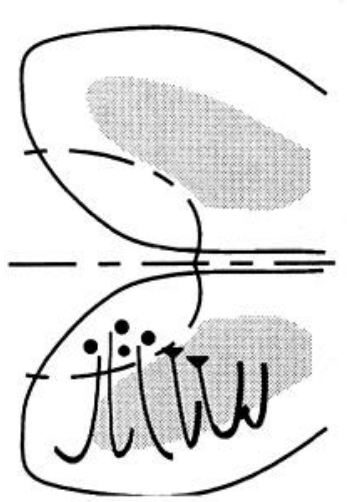

lateral view

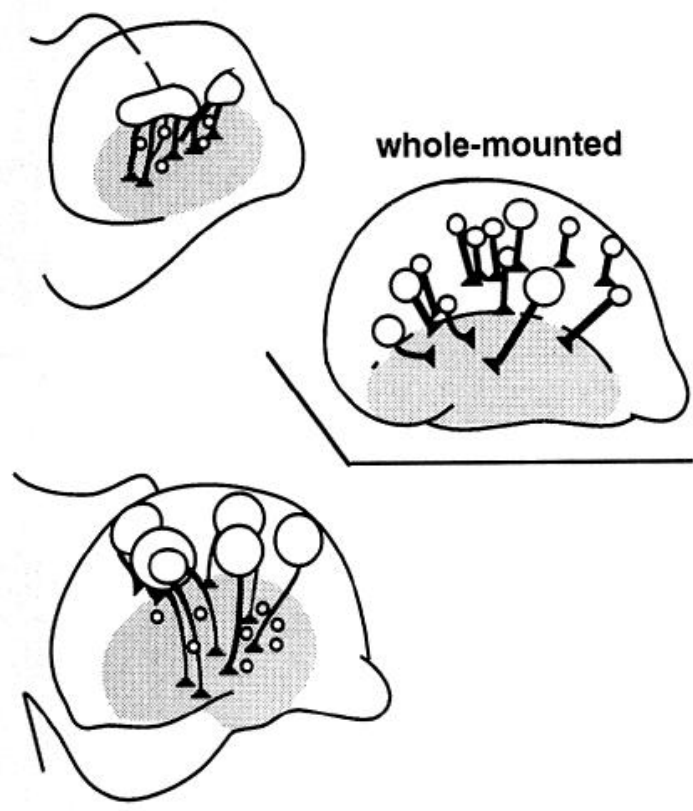

$1000 \mu \mathrm{m}$

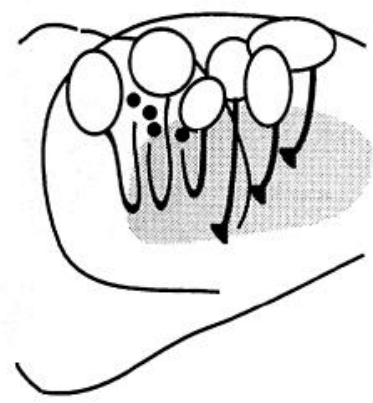

Figure 7. Summary diagram of the course followed by corticofugal fibers between E11.5 and E13.5 in hamsters. The results of injections performed on 13 flattened whole-mounted E11.5 telencephalic vesicles are summarized on the right. At E11.5, cortical axons labeled from the lateral-most sites enter the basal telencephalon (Telenceph.). Retrogradely labeled cells are associated with efferent fibers in the LGE. At E12.5, most fibers accumulate in the LGE. Cells are retrogradely labeled in the LGE (regions labeled with small white circles). At E13.5, fibers labeled from caudal cortical regions, but not from rostral regions, enter the diencephalon (Dienceph.). Thalamic cells are retrogradely labeled (regions with small dark circles) from caudal cortical areas. The left side shows trajectories in the horizontal plane, as viewed from the dorsal aspect. The right side shows trajectories in the vertical plane, as viewed from the lateral aspect of the brain. The GE is indicated in gray; rostral is to the right. Injection sites shown on the lateral views are the open circles.

the MGE. In a few experiments in which the telencephalic vesicle explants were kept attached to the thalamus, a higher number of corticofugal fibers reached the center of the MGE and pursued their course toward the thalamus (data not shown). Dye injections in the cortex labeled sparse cell bodies in the LGE intermingled with cortical axons, suggesting that LGE-cortical projections developed in these explants.

Close examination of the explants under both light (transmit- ted) and epifluorescent illumination showed that the region of the GE toward which corticofugal fibers were seen to converge was distinct from the surrounding tissue in that it appeared as a restricted and clear area under transmitted light (Fig. 8A). Small DiI injections in this area retrogradely labeled cells in the cortex as well as a restricted, rostrocaudally elongated group of cells in the lateral part of the LGE. Thus, large numbers of fibers arising from both the cortex and the LGE converged toward a subregion 
Table 2. Cultures of whole telencephalic vesicles or cocultures of cortex and GE

\begin{tabular}{lccc} 
Experimental conditions & Mouse & Hamster \\
\hline "Whole" telencephalic vesicles & DiI site & & \\
$(\# 1)$ & Cortex & 12 & 11 \\
& GE & 8 &
\end{tabular}

Neocortex/whole GE

(\#2)

43

Neocortex/lateral GE

(\#3)

(\#4)

(\#5)

LGE at the rostral or caudal border of cortex 3

Neocortex/medial GE

(\#7)

8

8

Controls

Neocortex/neocortex (\#8) 4

Neocortcx/brainstem 8

Neocortex/superior colliculus (\#9) 8

Number of cases analyzed in each experimental condition. Numbers in parentheses correspond to configuration in Figure $10 B$.

located in the center of the MGE. Cortical axons arising from caudal aspects of the cortex ran ventrally to the labeled cells in the LGE, whereas axons arising from other cortical regions ran across them.

\section{Development of fibers in cocultures of cortex and GE}

When a cortical explant was placed next to an explant comprising the entire GE, and both were oriented as in situ, corticofugal axons crossed the frontier and followed trajectories similar to those observed in the explants of "whole" telencephalic vesicles (Fig. 8).

When a cortical explant was placed next to an explant comprising the lateral subdivision of the GE (cortex + LGE cocultures), both explants reproducing the normal relative orientations of both structures, cortical axons formed fascicles that extended far into the LGE explant. In the median zone of the LGE explant, we always observed a small area reached by several fascicles arising from any rostrocaudal level. Among cocultures, a varying proportion of fibers labeled from the cortical explant (half of them in some cases) stopped in this region, which appeared as a clear spot under transmitted light (Fig. 9A,B). A few fibers entered and remained within this area where they defasciculated and formed a ball (Fig. 9C). Some fascicles were observed to be deflected just before reaching this area. Fascicles that did not end there extended in the rest of the LGE explant. They never exhibited a defasciculated aspect.

When both explants were placed in a manner that was different from their normal in vivo orientation (for instance, with the LGE explant facing the median side of the cortical explant; see Figs. $9 F$, 10 ), some fascicles of cortical axons again converged toward a small area at the median border of the explant where they remained, whereas other fascicles extended largely into the LGE explant, independently from its lateromedian orientation. When we placed LGE explants caudally or rostrally to cortical explants (Table 2), we observed that some cortical axons running close to the frontier with the LGE left the fascicles, grew into the LGE explant, and again ended in a restricted area of the LGE.

Because a restricted area at the median border of the LGE was able to orient the growth of a varying proportion of cortical axons in neocortex/LGE cocultures, whereas almost all corticofugal axons converged toward the center of the GE in neocortex/GE cocultures, we made cocultures of neocortex and MGE explants. When the normal relative orientation of both structures was respected, with the lateral aspect of the MGE facing the median aspect of the cortical explant (Fig. 9D,E), cortical axons stopped within the lateral border of the MGE explant, close to the frontier with the neocortex, and formed a large stump in some cases: As in cultures of whole telencephalic vesicle explants and in neocortex/GE or LGE cocultures, the region in which cortical fibers seemed to have stopped appeared as a small clear area under transmitted light (Fig. $9 D$ ). When the normal relative orientation of both explants was disrupted, with the MGE explant adjacent to the median aspect of the cortical explant (Figs. 9G, 10), cortical axons then coursed across the MGE, but virtually all of them converged toward a small region located along its lateral border.

\section{Development of fibers in cocultures of cortex and colliculus, brainstem, or cortex}

To assess whether only the GE or, alternatively, other regions of the CNS were able to orient the growth of cortical fibers in cocultures, we made cocultures between cortical and collicular, brainstem, or cortical explants. In cocultures of cortcx and colliculus, cortical axons did not grow at all into the collicular explant, suggesting that the collicular explant was not permissive for the growth of corticofugal fibers (Fig. 10). Some fibers were seen to grow at the interface between each explant, and they did not seem to stop at any particular level. In cocultures of cortex and brainstem or cortex, small fascicles of cortical axons crossed the frontier and extended into the adjacent explant (Fig. 9H,I). Thus, these explants were growth-permissive for cortical fibers. In contrast to the GE explants, however, cortical and brainstem explants were not able to orient in any particular way the trajectories of cortical fibers. The cortical fibers did not change their orientation after crossing the frontier, neighboring fascicles often diverged in the explants, and ncither isolated fibcrs nor fiber fascicles converged toward any particular region of the brainstem or cortical explants.

\section{DISCUSSION}

In this study, we describe the growth pattern of the earliest fibers that comprise the thalamocortical and corticothalamic projections. The development of these pathways follows a characteristic sequence, which is summarized in Figure 11. Our main findings are that (1) both thalamic and cortical fibers seem to pause within the GE for some time during their progression to their respective targets; (2) neurons in the mantle region of the lateral and medial subdivisions of the GE send carly and transitory projections toward the cortex and the thalamus, respectively, at stages when thalamic and cortical fibers are growing toward or into the $\mathrm{GE}$; and (3) cocultures of cortical and MGE or LGE explants show a dirccted growth of cortical fibers toward the GE. We also observed a reorganization in the trajectories, a defasciculated growth of thalamic and cortical fibers in the GE region, and a close apposition between cortical growth cones and certain cells 

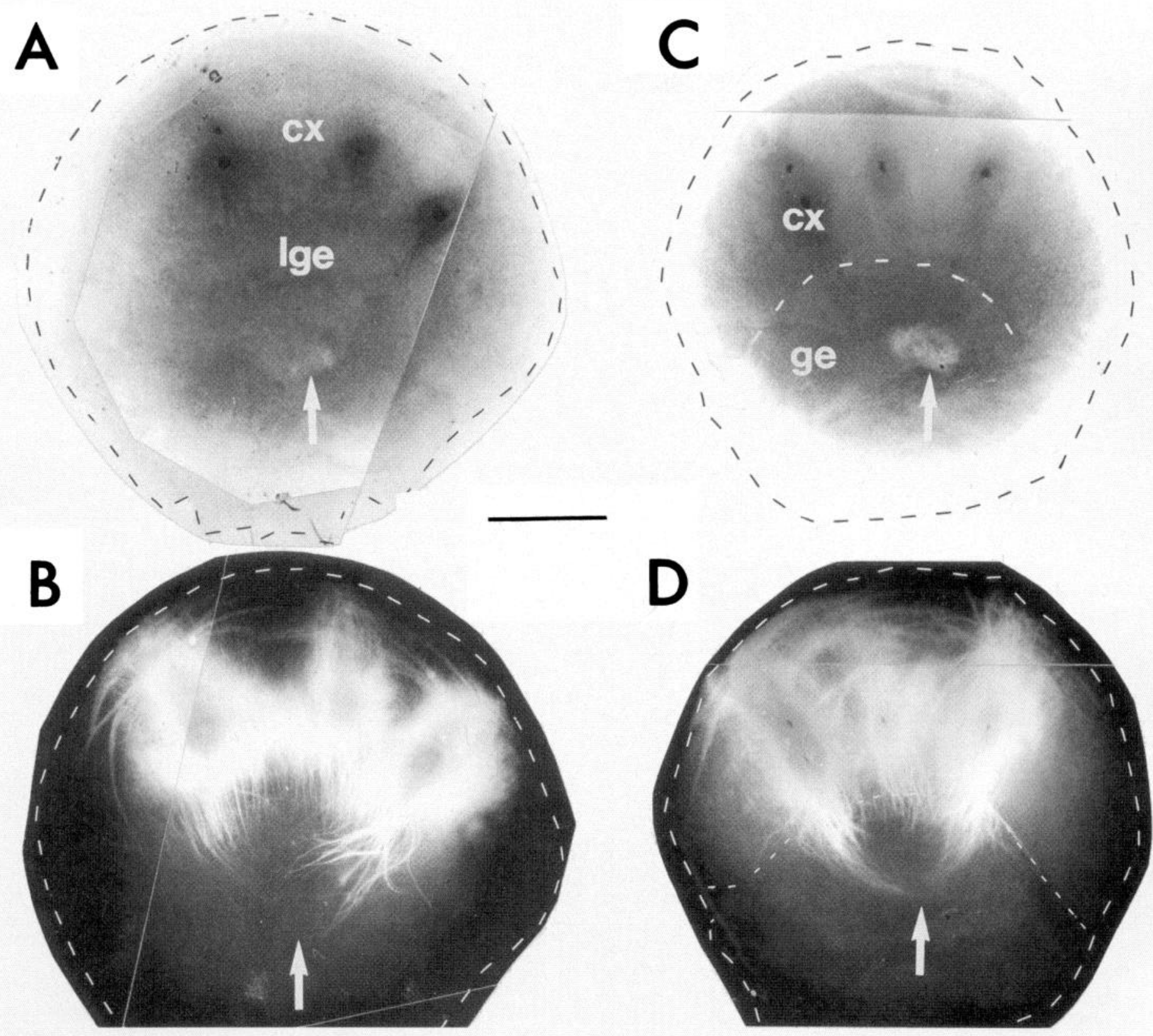

Figure 8. $A, B$, Culture of an entire telencephalic vesicle; $C, D$, coculture of neocortex $(c x)$ and $\mathrm{GE}$ ( $g e$ ). Explants are viewed from their ventricular side after $4 \mathrm{~d}$ of growth. Rostral is left, dorsal is up. Injection sites of DiI are visible as dark spots in transmitted light $(A, C)$, and an optically less dense area (white arrow) is visible in both cases in the GE, below the LGE (lge). In both cultures, most dye-labeled corticofugal axons $(B, D)$ enter the LGE and some of them converge toward a small site below the LGE, which corresponds to the more transparent areas visible in $A$ and $C$. Scale bar, $1000 \mu \mathrm{m}$.

with complex morphologies in the GE. Taken together, our findings suggest that the mantle region of the GE is a prominent way-station in the pathway between thalamus and cortex and may serve as an intermediate target for cortical and probably thalamic fibers.

\section{Growth of thalamic and cortical fibers toward the GE}

The first fibers that exit the embryonic neocortex originate from preplate cells in the lateral-most aspect of the cortical wall. These cells are the closest to the exit point from the neocortex and may be generated earliest in view of the lateromedian gradient of maturation of the cortical wall in mammals (Angevine and Sidman, 1961; Berry and Rogers, 1965; Shimada and Langman, 1970;
Brückner et al., 1976; Crossland and Uchwacht, 1982; Luskin and Shatz, 1985; Marin-Padilla, 1988; Rakic, 1988; Jackson et al., 1989). As shown by retrograde labeling experiments (data not shown), axons from these preplate cells are also the first to reach the GE. Unlike those in ferrets (McConnell et al., 1989), they apparently do not reach the dorsal thalamus much before the later-outgrowing axons from the cortical plate cells do. Injections of DiI in the thalamus in all cases resulted in labeling of both preplate and cortical plate cells.

A surprising observation is that the cortical fibers accumulate for $1 \mathrm{~d}$ (between E11.5 and E12.5) within the LGE before pursuing their growth through the telodiencephalic sulcus. During this 

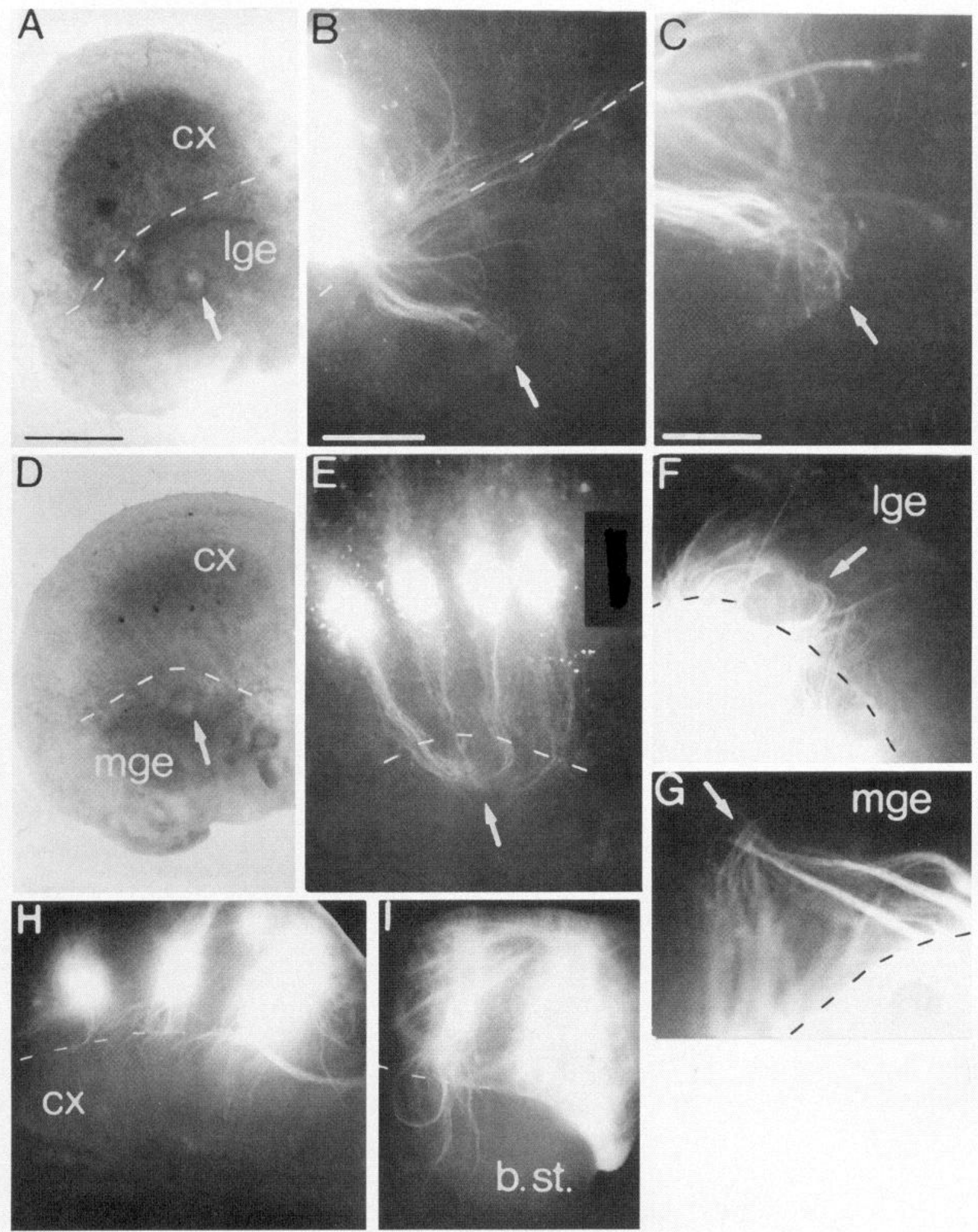

Figure 9. Cocultures of neocortex with $\operatorname{LGE}(A, B, C, F)$, MGE $(D, E, G)$, neocortex $(H)$, and brain stem $(I)$. The explants were from E13 mouse embryos. The injection sites of DiI in the cortex are visible under fluorescent illumination. $A-C$, Cortex/LGE coculture with the LGE (lge) explant placed at the lateral border of the cortex $(c x)$. B, Labeled corticofugal fibers are shown that converge toward a restricted area within the LGE (arrow), which appears clear under light microscopy $(A)$. Many fibers seem to have stopped there $(C)$, and some fibers make a clear turn to reach this area. $D$, $E$, Neocortex/MGE coculture: the MGE ( $m g e$ ) explant is placed at the lateral border of the neocortex. $E$, Labeled corticofugal axons are shown that converge toward a small area at the lateral border of the MGE explant (arrow), which appears clear under light microscopy $(D)$ ). $F$, Cortex/LGE coculture with the median border of the LGE explant placed at the median border of the cortex. Fascicles of axons labeled from the cortical explant either largely extend in the LGE explant or turn and end in a small area of the LGE explant (arrow) close to the frontier. $G$, Cortex/MGE coculture with the MGE explant placed at the median border of the cortex. The fascicles of cortical axons converge toward the lateral border of the MGE explant. $H, I$, In these cocultures the corticofugal axons form small fascicles that course throughout the adjacent explant. $b$. st., Brainstem. $A-I$, Dotted lines show the frontiers between each explant. Scale bars: $A, D, F, H, I, 1000 \mu \mathrm{m} ; B, E, F, 500 \mu \mathrm{m} ; G, 380 \mu \mathrm{m} ; C, 250 \mu \mathrm{m}$. 
A

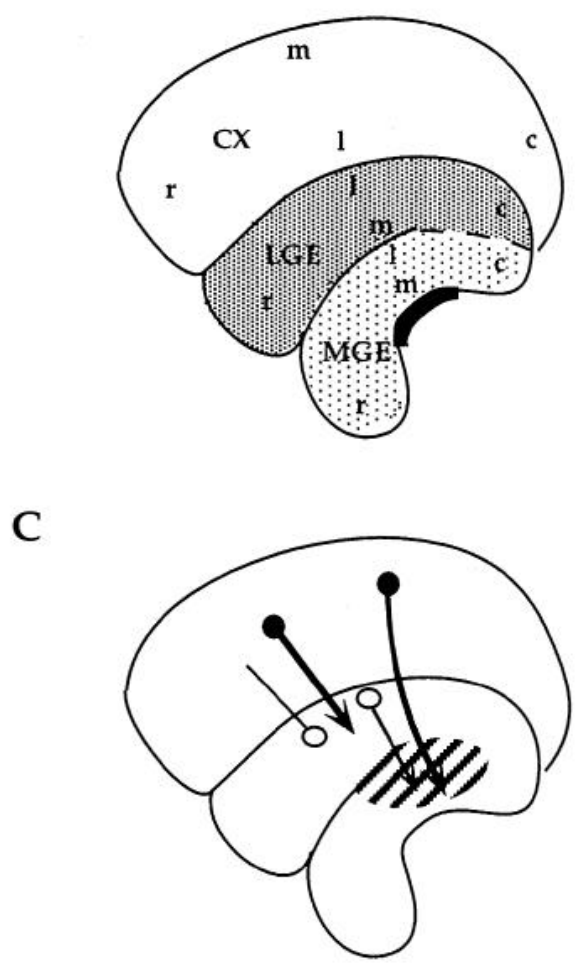

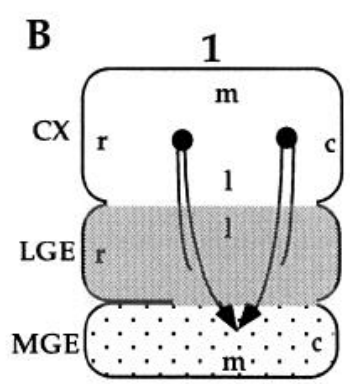
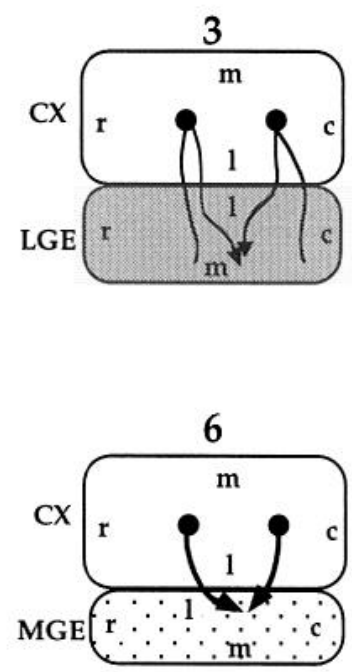

8

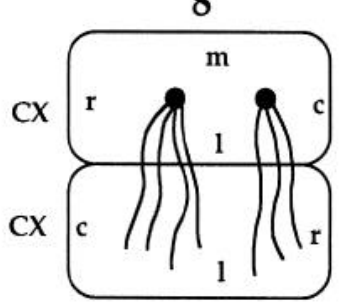

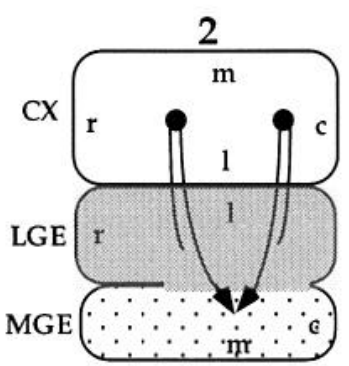
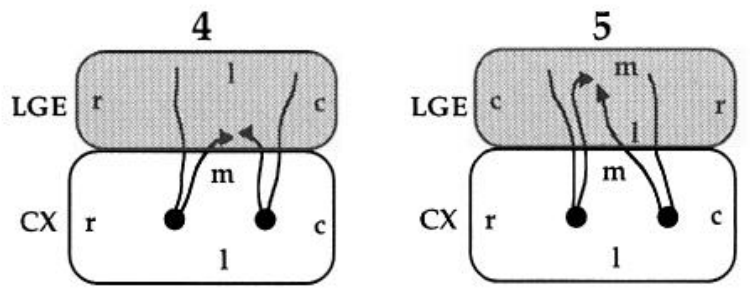

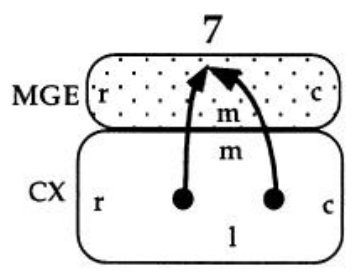

9

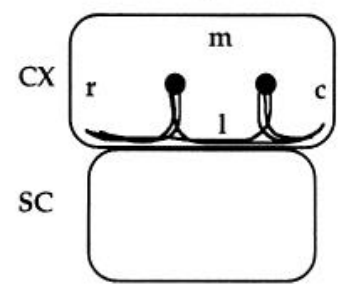

Figure 10. Summary diagram showing the results of coculture experiments. $A$, The telencephalic vesicle as viewed from the ventricular side and regions used in the cocultures; $B$, schemes of the cocultures showing the DiI injection sites (dark spots) and the trajectories of labeled corticofugal fibers in the cultures. Arrowheads indicate fibers that converge and end in a subregion of the GE explants. 1: "Whole" telencephalic vesicle explant; 2: coculture between neocortex and GE; 3-5: cocultures of neocortex and LGE in three distinct relative orientations; 6-7: cocultures of neocortex and MGE in two distinct relative orientations; 8-9: control cocultures between two explants of neocortex $(8)$ and between neocortex and superior colliculus ( 9 ). $C$, Interpretative scheme of the culture and coculture results. In whole telencephalic vesicle explants, corticofugal fibers end among cells in the LGE or project toward a subpart of the GE, indicated by stripes. Cells in the LGE project toward the neocortex or toward the same area of the GE as reached by the corticofugal fibers. This pattern closely resembles that observed in vivo. In cocultures of neocortex with GE, LGE, or MGE, corticofugal fibers also converge toward a subregion of the GE. In all parts of the figure, the rostral $(r)$ and caudal $(\mathrm{c})$, medial $(\mathrm{m})$ and lateral $(l)$ sides are indicated by the small letters.

time, thalamic fibers extend into the MGE, and a few of them reach the LGE. These observations imply that both pioneer cortical and thalamic fibers grow independently from each other but converge in the GE: specifically, from cortex to LGE and from thalamus to MGE.

\section{Retrogradely labeled cells among extending fibers}

In the intermediate zone of the cortical wall and around the ventricular angle, efferent cortical fibers labeled with DiI are intermingled with cells that are also labeled. Labeled cells are also found in the LGE, although only for a short period (E11.5E12.5). These cells either could be labeled transcellularly (Gode- ment et al., 1987) or could send a process within or toward the cortical wall. It is unlikely that they would be labeled transcellularly, because (1) careful examination of their morphologies shows that in all cases they indeed sent a process toward and (as could sometimes be observed in a single section) into the injection site; (2) we never observed labeled radial glial cells far from the injection site, although cortical fibers grow within a lattice of radial glial processes that cover the whole extent of the cortical wall (Rakic, 1972, 1988; Gadisseux et al., 1989) and GE (Liu and Graybiel, 1992; our unpublished observations), indicating that transcellular labeling was absent or kept minimal in our material; (3) cells (both in the cortical wall and GE) can be labeled similarly 

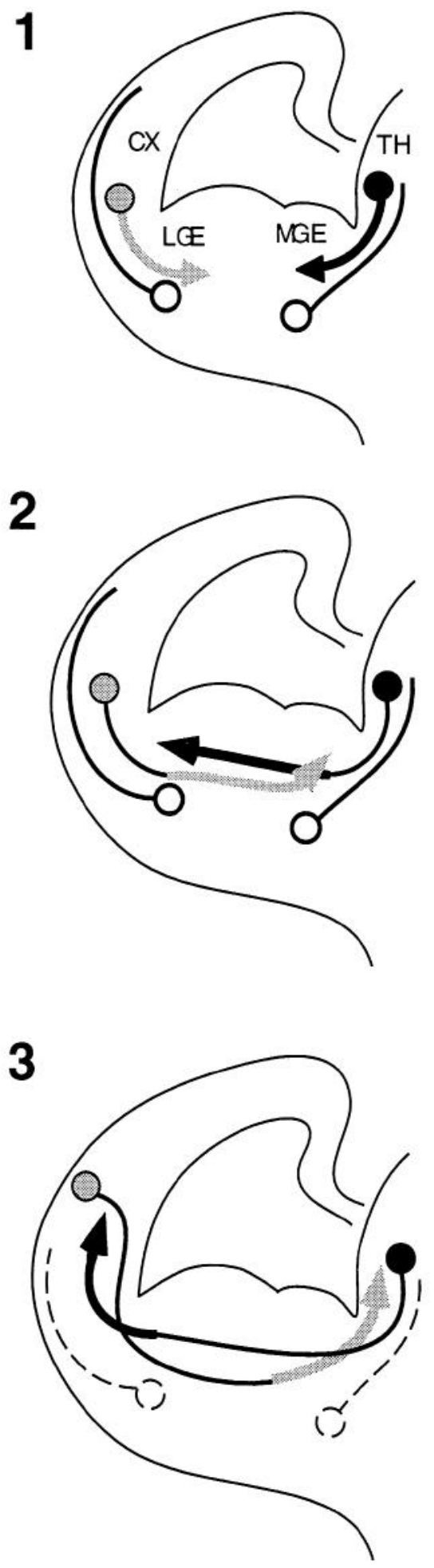

Figure 11. Early steps in the development of the projections between thalamus $(T H)$ and cortex $(C X)$ and their relationships with the early efferent projections from the basal telencephalon. 1, Cortical axons from preplate cells (gray) begin to enter the LGE, and axons from dorsal thalamic cells (black) begin to enter the MGE. Reciprocally, cells in the LGE (open circle) send a projection to the cortex, and cells in the MGE (open circle) send a projection to the dorsal thalamus. 2, Thalamic and cortical fibers distribute within the GE, but do not enter the cortical wall or the dorsal diencephalon, respectively. The projections between the LGE and the embryonic neocortex show a rostrocaudal differentiation. 3, Thalamic and cortical fibers have reached their target region. The efferent projections from the GE to the cortex and the thalamus become reshaped or reduced. after in vivo injections of DiI and WGA-HRP; and (4) our immunohistochemical data indicate that Map2-positive neuronal cells (as well as calbindin-positive cells) are found in these regions, with shapes and distributions closely fitting those of the DiIlabeled cells. In the cortical wall, these cells extend long processes toward the cortical plate, and they obviously could be labeled retrogradely by our injections. Many of these Map2-positive neurons also express GABA (Cobas et al., 1991; Delrio et al., 1992; our unpublished observations).

\section{Early efferent projections from the GE}

A novel finding in this study is that cells of the LGE project axons to the cortical wall at stages when cortical cells extend an axon to the GE and likewise that cells of the MGE send an early projection to the dorsal thalamus when thalamic cells extend an axon through the telodiencephalic sulcus. Because the striatum does not project back onto the neocortex after birth and in the adult (Iñiguez et al., 1990; Gerfen, 1992), this early corticopetal projection should be present only transiently. In the LGE, the retrogradely labeled cells were colocalized with juvenile neurons and calbindin-positive cells. We could not detect double-labeled cells, probably because the photo-oxidation process strongly reduced the immunoreactivity of cells. In the rat, Liu and Graybiel (1992) described an early and transient population of calbindin-positive cells in the developing striatum that are closely related to a pattern of calbindin-immunoreactive fibers between the LGE and the neocortex, and it is likely that these projections are the same as those we have observed by DiI-labeling.

The projection from the MGE to the thalamus arises in a region containing a dense population of neurons. Studies performed at later stages in rats have identified a population of neurons in the internal capsule that are transient and send projections to the dorsal thalamus (Mitrofanis and Baker, 1993; Mitrofanis, 1994). The cells engaged in the early projection that we have observed could be equivalent to the perireticular cells observed in rats. In hamsters, they both develop and send projections to the thalamus very early (i.e., E11.5), coincidental with the growth of pioneer dorsal thalamic fibers.

Thus, as they enter the basal telencephalon (GE), cortical and thalamic projections can interact with two early efferent projections arising from LGE and MGE cells that are located close to the limit between the two compartments they will join. These two output projections, apparently far-reaching, might well play symmetrical roles during development by participating in the guidance of the first cortical and thalamic fibers as they exit their domain of origin, e.g., by processes of fiber-fiber fasciculation. It is noteworthy that the LGE-cortical projection is transient, vanishing at E13.5; its potential role in the guidance of cortical fibers would then be restricted to the earliest (pioneer) fibers that leave the cortical wall, most of which project down to thalamus or mesencephalic targets. In addition, axocellular interactions could occur between the growing cortical (and maybe thalamic) axons and cells distributed along their pathway. At the ventricular angle, we frequently observed associations between growth cones of cortical axons and cells expressing CaBP28K that are distributed in the intermediate zone, some of which display neuronal morphologies.

The early cortical and thalamic projections to the GE, which match the two reverse projection systems from LGE to cortex and from MGE to thalamus, define two early "neopallial-LGE" and "thalamic-MGE" domains. It is interesting to note that each domain also coincides with the domains of expression of several 
developmental genes. Indeed, Gbx2, a gene that encodes a homeodomain protein, is expressed in the MGE and the dorsal thalamus (Bulfone et al., 1993b), and Otx1 and Otx2 are expressed in the cortical wall and the LGE (Simeone et al., 1993). A first step in the development of the reciprocal thalamocortical connections may therefore be the establishment of reciprocal projections within each domain, i.e., between cortex and LGE and thalamus and MGE.

\section{Growth of fibers within the GE}

As cortical and thalamic fibers both enter the mantle region of the LGE and MGE, they shift their directions of growth, become defasciculated, and bear complex growth cones. Furthermore, during the time in which cortical fibers accumulate in the LGE, some of their growth cones are observed to be closely apposed to well differentiated, calbindin-positive cells, which raises the possibility that they interact with these cells. Calbindin-positive cells were observed both close to the proliferative neuroepithelium and in the mantle region of the $\mathrm{GE}$, which at these ages contains postmitotic cells, in particular neurons (Menezes and Luskin, 1994; Porteus et al., 1994). In view of their large size and complex morphologies, it is likely that these cells are neurons. They are clearly different from the radial glia that are RC2-positive (Fishell et al., 1995; our unpublished observations).

Taken together, our results suggest that the mantle zones of both LGE and MGE constitute a decision region for cortical and thalamic fibers. In addition to the specific reorientation of growing corticofugal fibers within the GE, apparent pausing of the fibers in this region, the occurrence of complex growth cones and the axocellular contacts suggest a role of $\mathrm{LGE}$ and MGE as intermediate targets for these fibers, because these features are hallmarks of growing axons within intermediate targets (Tosney and Landmesser, 1985; Caudy and Bentley, 1986; Bovolenta and Mason, 1987; Godement et al., 1990; Sretavan, 1993; Godement et al., 1994; Marcus et al., 1995).

This conclusion is also supported by the results of coculture experiments in which we tested whether the GE alone could orient specifically the growth and trajectories of corticofugal fibers. In control cocultures (cortical-collicular, -brainstem, or -cortical cocultures), cortical fibers were never observed to follow oriented trajectories within the adjacent explant. In cocultures of cortex with GE, an oriented growth of cortical fibers occurs toward the GE, more precisely toward a region in the medial ridge of the GE, in several types of explant cocultures, either intact cortical-GE explants or cortical-LGE and -MGE cocultures. Contact interactions between cortical fibers and cells in the GE may be involved in orienting the growth of cortical fibers in the GE. LGE-derived axons were seen to converge toward the same area as cortical fibers in the GE. Alternatively, diffusible cues in the GE might orient the growth of cortical fibers within this structure. Our observations suggest that both types of mechanisms could be used, but additional experiments are needed to determine their relative contribution to the pathfinding of cortical fibers.

Previous studies about the development of thalamocortical projections implicated the subplate (Allendoerfer and Shatz, 1994), an intermediate target located within the cortical wall. In the present study, we define the GE, another intermediate target implicated at a very early stage in the development of thalamocortical projections. In contrast to the subplate, the GE is a structure embryologically independent from the cortical wall as well from the dorsal thalamus (Lammers et al., 1980; Sidman and Rakic, 1982). Its location on the path between thalamus and cortex is well suited to guide the navigation of the first thalamic and cortical fibers along their trajectory. To our knowledge, the GE constitutes the first example of an intermediate target described in the basal telencephalon.

\section{REFERENCES}

Allendoerfer KL, Shatz CJ (1994) The subplate, a transient neocortical structure: its rolc in the development of connections between thalamus and cortex. Annu Rev Neurosci 17:185-218.

Angevine JB, Sidman RL (1961) Autoradiographic study of ccll migration during histogenesis of cerebral cortex in the mouse. Nature 192:766-768.

Bayer SA, Altman J (1990) Development of layer I and the subplate in the rat neocortex. Exp Neurol 107:48-62.

Berry M, Rogers AW (1965) The migration of neuroblasts in the developing cerebral cortex. J Anat 99:691-709.

Blakemore C, Molnàr Z (1990) Factors involved in the establishment of specific interconnections between thalamus and cerebral cortex. In: The brain (Cold Spring Harbor Symposia on Quantitative Biology, ed), pp 491-504. Cold Spring Harbor, NY: Cold Spring Harbor Laboratory.

Bovolenta P, Mason CA (1987) Growth cone morphology varies with position in the developing mouse visual pathway from retina to first targets. J Neurosci 7:1447-1460.

Brion J-P, Guilleminot J, Couchie D, Flament-Durand J, Nunez J (1988) Both adult and juvenile tau microtubule-associated proteins are axon specific in the developing and adult rat cerebellum. Neuroscience 25:139-146.

Brückner G, Mares V, Biesold D (1976) Neurogenesis in the visual system of the rat: an autoradiographic investigation. J Comp Neurol $166: 245-256$

Bulfone A, Puelles L, Porteus MH, Frohman MA, Martin GR, Rubenstein JLR (1993b) Spatially restricted expression of Dlx-1, Dlx-2(Tes1), Gbx-2, and Wnt-3 in the embryonic day 12.5 mouse forebrain defines potential transverse and longitudinal segmental boundaries. J Neurosci 13:3155-3172

Caudy M, Bentley D (1986) Pioneer growth cone steering along a series of neuronal and non-ncuronal cues of different affinities. $J$ Neurosci 6:1781-1795.

Cobas A, Fairen A, Alvarezbolado G, Sanchez MP (1991) Prenatal development of the intrinsic neurons of the rat neocortex: a comparative study of the distribution of GABA-immunoreactive cells and the GABA $_{\mathrm{A}}$ receptor. Neuroscience 40:375-397.

Cornel E, Holt CE (1992) Precocious pathfinding: retinal axons can navigate in an axonless brain. Neuron 9:1001-1011.

Crossland WJ, Uchwacht CJ (1982) Neurogenesis in the central visual pathway of the golden hamster. Dev Brain Res 5:99-103.

De Carlos JA, O'Leary DDM (1992) Growth and targeting of subplate axons and establishment of major cortical pathways. J Neurosci 12:1194-1211.

Dechesne CJ, Thomasset M (1988) Calbindin (CaBP28 kDa) appearance and distribution during development of the mouse inner ear. Dev Brain Res 40:233-242

Delrio JA, Soriano E, Ferrer I (1992) Development of GABAimmunoreactivity in the neocortex of the mouse. J Comp Neurol 326:501-526.

Dodd J, Jessell TM (1988) Axon guidance and the patterning of neuronal projections in vertebrates. Science 242:692-699.

Felsenfeld DP, Hynes MA, Skoter KM, Furley AJ, Jessell TM (1994) TAG-1 can mediate homophilic binding, but neurite outgrowth on TAG-1 requires an L1-like molecule and $\beta 1$ integrins. Neuron 12:675-690.

Fishell G, Blazeski R, Godement P, Rivas R, Wang LC, Mason CA (1995) Optical microscopy 3: tracking fluorescently labeled neurons in developing brain. FASEB J 9:324-334.

Gadisseux J-F, Evrard P, Misson J-P, Caviness VS (1989) Dynamic structure of the radial glial fiber system of the developing murine cerebral wall: an immunocytochemical analysis. Dev Brain Res 50:55-67.

Gerfen CR (1992) The neostriatal mosaic: multiple levels of compartmental organzation. Trends Neurosci 15:133-139.

Ghosh A, Shatz CJ (1992) Pathfinding and target selection by developing geniculocortical axons. J Neurosci 12:39-55.

Ghosh A, Antonini A, McConnell SK, Shatz CJ (1990) Requirement for subplate neurons in the formation of thalamocortical connections. Nature 347:179-181. 
Godement P (1994) Axonal pathfinding at the optic chiasm and at decision regions: control of growth cone motility, guidance, and cellular contacts. Semin Dev Biol 5:381-389.

Godement P, Salaün J, Mason CA (1990) Retinal axon pathfinding in the optic chiasm: divergence of crossed and uncrossed fibers. Neuron 5:173-186.

Godement P, Vanselow J, Thanos S, Bonhoeffer F (1987) A study in developing visual systems with a new method of staining neurones and their processes in fixcd tissuc. Devclopment 101:697-713.

Godement P, Wang LC, Mason CA (1994) Retinal axon divergence in the optic chiasm: dynamics of growth cone behavior at the midline. J Neurosci 14:7024-7039.

Goodman CS, Shatz CJ (1993) Developmental mechanisms that generate precise patterns of neuronal connectivity. Cell 72/Neuron 10[Suppl]:77-98.

Harris WA, Holt CE (1990) Early events in the embryogenesis of the vertebrate visual system. Annu Rev Neurosci 13:155-169.

IIo RK, Goodman CS (1982) Peripheral pathways are pioneered by an array of central and peripheral neurones in grasshopper embryos. Nature 297:404-406.

Iñiguez C, De Juan J, Al-Majdalawi A, Gayoso MJ (1990) Postnatal development of striatal connections in the rat: a transport study with wheat germ agglutinin-horseradish peroxidase. Dev Brain Res 57:43-53.

Jackson CA, Peduzzi JD, Hickey TL (1989) Visual cortex development in ferret. I. Genesis and migration of visual cortical neurons. J Neurosci 9:1242-1253.

Kostovic I, Molliver ME (1974) A new interpretation of the laminar development of cerebral cortex: synaptogenesis in different layers of neopallium in the human fetus. Anat Rec 178:395.

Lammers GJ, Gribnau AAM, ten Donkelaar HJ (1980) Neurogenesis in the basal forebrain in the chinese hamster (Cricetulus griseus). Anat Embryol 158:193-211.

Liu F-C, Graybiel AM (1992) Transient calbindin-D28K-positive systems in the telencephalon: ganglionic eminence, developing striatum and cerebral cortex. J Neurosci 12:674-690.

Luskin MB, Shatz CJ (1985) Neurogenesis of the cat's primary visual cortex. J Comp Neurol 242:611-631.

Marcus RC, Blazeski R, Godement P, Mason CA (1995) Retinal axon divergence in the optic chiasm: uncrossed axons diverge from crossed axons within a midline glial specialzation. J Neurosci 15:3716-3729.

Marin-Padilla M (1978) Dual origin of the mammalian neocortex and evaluation of the cortical plate. Anat Embryol 152:109-126.

Marin-Padilla M (1988) Early ontogenesis of the human cerebral cortex. In: Development and maturation of cerebral cortex (Peters A, Jones EG, eds), pp 1-34. New York: Plenum.

McConnell SK, Ghosh A, Shatz CJ (1989) Subplate neurons pioneer the first axon pathway from the cerebral cortex. Science 245:978-982.

Menezes JRL, Luskin MB (1994) Expression of neuron-specific tubulin defines a novel population in the proliferative layers of the developing telencephalon. J Neurosci 14:5399-5416.

Miller B, Chou L, Finlay BL (1993) The early development of thalamocortical and corticothalamic projections. J Comp Neurol 335:16-41.

Mitrofanis J (1994) Development of the thalamic reticular nucleus in ferrets with special reference to the perigeniculate and perireticular cell groups. Eur J Neurosci 6:253-263.

Mitrofanis J, Baker GE (1993) Development of the thalamic reticular and perireticular nuclei in rats and their relationship to the course of growing corticofugal and corticopetal axons. J Comp Neurol 338:575-587.

Mitrofanis J, Guillery RW (1993) New views of the thalamic reticular nucleus in the adult and the developing brain. Trends Neurosci $16: 240-245$.
Molnàr Z, Blakemore C (1995) How do thalamic axons find their way to the cortex? Trends Neurosci 18:389-397.

O'Leary DDM, Koester SE (1993) Development of projection neuron types, axon pathways and patterned connections of the mammalian cortex. Neuron 10:991-1006.

Placzek M, Tessier-Lavigne M, Yamada Y, Dodd J, Jessell TM (1990) Guidance of developing axons by diffusible chemoattractants. In: The brain (Cold Spring Harbor Symposia on Quantitative Biology, ed), pp 279-289. Cold Spring Harbor, NY: Cold Spring Harbor Laboratory.

Porteus MH, Bulfone A, Liu JK, Puelles L, Lo LC, Rubenstein JL (1994) DLX-2, MASH-1, and MAP-2 expression and bromodeoxyuridine incorporation define molecularly distinct cell populations in the embryonic mouse forebrain. J Neurosci 14:6370-6383.

Rakic P (1972) Mode of cell migration to the superficial layers of fetal monkey neocortex. J Comp Neurol 145:61-84.

Rakic P (1988) Specification of cerebral cortical areas. Science 241:170-176.

Raper JA, Bastiani M, Goodman CS (1983b) Pathfinding by neuronal growth cones in grasshopper embryos. II. Selective fasciculation onto specific axonal pathways. J Neurosci 3:31 41.

Serafini T, Kennedy TE, Galko MJ, Mirzayan C, Jessell TM, TessierLavigne M (1994) The netrins define a family of axon outgrowthpromoting proteins homologous to $C$. elegans UNC-6. Cell $78: 409-424$

Shimada M, Langman J (1970) Cell proliferation, migration and differentiation in the cerebral cortex of the golden hamster. J Comp Neurol 139:227-224.

Shirasaki R, Tamada A, Katsumata R, Murakami F (1995) Guidance of cerebellofugal axons in the rat embryo: directed growth towards the floor plate and subsequent elongation along the longitudinal axis. Neuron 14:961-972.

Sidman RL, Rakic P (1982) Development of the human central nervous system. In: Histology and histopathology of the nervous system (Adams WH, Adams RD, eds), pp. 3-145. Illinois: C.C. Thomas.

Simeone A, Acampora D, Mallamaci A, Stornaiuolo A, Dapice MR, Nigro V, Boncinelli E (1993) A vertebrate gene related to orthodenticle contains a homeodomain of the bicoid class and demarcates anterior neuroectoderm in the gastrulating mouse embryo. EMBO J 12:2735-2747.

Sretavan DW (1993) Pathfinding at the mammalian optic chiasm. Curr Opin Neurobiol 3:45-52.

Sretavan DW, Feng L, Pure E, Reichardt LF (1994) Embryonic neurons of the developing optic chiasm express $\mathrm{L} 1$ and CD44, cell surface molecules with opposing effects on retinal axon growth. Neuron 12:957-975.

Tessier-Lavigne M, Placzek M, Lumsden AGS, Dodd J, Jessell TM (1988) Chemotropic guidance of developing axons in the mammalian central nervous system. Nature 336:775-778.

Tosney KW (1991) Cells and cell-interactions that guide motor axons in the developing chick embryo. BioEssays 13:17-23.

Tosney KW, Landmesser LT (1985) Growth cone morphology and trajectory in the lumbosacral region of the chick embryo. J Neurosci 5:2345-2358.

Wilson SW, Easter SSJ (1991) A pioneering growth cone in the embryonic zebrafish brain. Proc Natl Acad Sci USA 88:2293-2296.

Wizenmann A, Thanos S, von Boxberg Y, Bonhoeffer F (1993) Differential reaction of crossing and non-crossing rat retinal axons on cell membrane preparations from the chiasm midline: an in vitro study. Development 117:725-735.

Yaginuma H, Shiga T, Oppenheim RW (1993) Mechanisms of axonal guidance used by interneurons in the chick embryo spinal cord. Perspect Dev Neurobiol 1:205-215. 